\title{
9) OECD
}

\section{lec}

Climate Change Expert Group

Paper No. 2019(5)

Designing the Article 6.4 mechanism: assessing selected baseline approaches and their implications

Luca Lo Re (IEA), Jane Ellis (OECD), Manasvini Vaidyula (OECD) and Andrew Prag (IEA/OECD) 


\section{ENVIRONMENT DIRECTORATE}

INTERNATIONAL ENERGY AGENCY

Cancels \& replaces the same document of 25 November 2019

Designing the Article 6.4 mechanism: assessing selected baseline approaches and their implications

The ideas expressed are those of the authors and do not necessarily represent views of the OECD, the IEA, or their member countries, or the endorsement of any approach described herein.

Luca Lo Re, Jane Ellis, Manasvini Vaidyula and Andrew Prag.

JT03455449 


\section{Foreword}

This document was prepared by the OECD and IEA Secretariats in response to a request from the Climate Change Expert Group (CCXG) on the United Nations Framework Convention on Climate Change (UNFCCC). The Climate Change Expert Group oversees development of analytical papers for the purpose of providing useful and timely input to the climate change negotiations. These papers may also be useful to national policy-makers and other decision-makers. Authors work with the CCXG to develop these papers. However, the papers do not necessarily represent the views of the OECD or the IEA, nor are they intended to prejudge the views of countries participating in the CCXG. Rather, they are Secretariat information papers intended to inform Member countries, as well as the UNFCCC audience.

Members of the CCXG are those countries who are OECD members and/or who are listed in Annex I of the UNFCCC (as amended by the Conference of the Parties in 1997 and 2010). The Annex I Parties or countries referred to in this document are: Australia, Austria, Belarus, Belgium, Bulgaria, Canada, Croatia, Czech Republic, Denmark, the European Community, Estonia, Finland, France, Germany, Greece, Hungary, Iceland, Ireland, Italy, Japan, Latvia, Liechtenstein, Lithuania, Luxembourg, Malta, Monaco, the Netherlands, New Zealand, Norway, Poland, Portugal, Romania, the Russian Federation, Slovak Republic, Slovenia, Spain, Sweden, Switzerland, Turkey, Ukraine, the United Kingdom of Great Britain and Northern Ireland, and the United States of America. Korea, Mexico, Chile and Israel are also members of the CCXG. Where this document refers to "countries" or "governments", it is also intended to include "regional economic organisations", if appropriate. 


\section{Acknowledgments}

The authors would like to thank in particular Marcia Rocha, Chiara Falduto, Simon Buckle (OECD) and Sara Moarif (IEA) for their thorough inputs on earlier drafts. The authors would also like to thank Lambert Schneider (Öko-Institut), Perumal Arumugam (UNFCCC), Benoit Leguet and Alice Pauthier (I4CE) for useful input on the topic of crediting baselines. In addition, the authors would like to thank Sweden for their written comments on the draft version of the paper, and delegates from Austria, Australia, Canada, Norway and Spain for providing oral comments at the October 2019 CCXG Meeting. In addition, the authors thank presenters and attendees at the October 2019 CCXG Global Forum on the Environment and Climate Change, whose views and feedback helped shape the final document. The authors would also like to thank Cyril Cassisa, Peter Levi, Tiffany Vass, Craig Hart, Carlos Fernandez Alvarez, Gergely Molnar and Claudia Pavarini (IEA) for their input on the sectoral deep dives.

The Secretariat would like to thank the Australia (Department of Foreign Affairs and Trade), European Commission, Finland (Ministry of the Environment), Germany (Federal Ministry for the Environment, Nature Conservation and Nuclear Safety), Japan (Ministry of the Environment), Netherlands (Ministry of Economic Affairs and Climate Policy), New Zealand (Ministry for the Environment), Norway (Ministry of Climate and Environment), Sweden (Swedish Environmental Protection Agency) and Switzerland (Federal Office for the Environment) for their direct funding of the CCXG in 2019, and the OECD and IEA for their in-kind support.

\section{Questions and comments should be sent to:}

Luca Lo Re (IEA) and Jane Ellis (OECD)

OECD Environment Directorate

46 Quai Alphonse le Gallo

92100 Boulogne-Billancourt

France

Email: luca.lore@iea.org and jane.ellis@oecd.org

All OECD and IEA information papers for the Climate Change Expert Group on the UNFCCC can be downloaded from: www.oecd.org/environment/cc/ccxg.htm 


\title{
Abstract
}

\author{
Designing the Article 6.4 mechanism: assessing selected baseline approaches and their \\ implications
}

Different options of methodological approaches for setting emission baselines are currently under consideration in the international climate negotiations. This paper examines options for baseline approaches for the Article 6.4 mechanism, and draws lessons from how baselines have been used for other market mechanisms. The paper highlights that the different approaches being discussed offer advantages and disadvantages in the context of Article 6.4. Moreover, the paper points out that a onesize-fits-all approach to setting baselines is unlikely to be appropriate for the new mechanism, given the variety of possible mitigation activity types and contexts. In particular, analysis of Clean Development Mechanism projects shows that a single baseline approach led to wide variations in baseline levels, implying the need to revise some methodologies if they are to be applied to Article 6.4. The paper also discusses benefits and implications for host Parties participating in the Article 6.4 mechanism, which may affect how Parties achieve their NDCs.

JEL Classifications: F53, Q54, Q56, Q58

Keywords: UNFCCC, carbon markets, Paris Agreement, Article 6, Kyoto Protocol, baselines, CDM

\section{Résumé}

\section{Conception du mécanisme de l'article 6.4 : évaluation d'approches pour établir de niveaux d'émissions de référence et leurs implications}

Différents options d'approches méthodologiques sont actuellement à l'étude, dans le cadre des négociations internationales sur le climat, en vue de définir des niveaux d'émissions de référence. Ce document analyse ces options qui pourraient être appliquées au mécanisme de l'article 6.4 et s'appuie sur les enseignements des niveaux de référence d'autres mécanismes de marché. Les différentes options en discussion présentent des avantages et des inconvénients dans le contexte de l'application de l'article 6.4. Par ailleurs, cette analyse souligne qu'il est peu probable qu'une seule approche puisse convenir pour le nouveau mécanisme, étant donné la diversité des activités d'atténuation envisageables et des différents contextes. En particulier, une analyse des projets du Mécanisme de Développement Propre montre qu'une seule approche a amené à l'établissement de niveaux de référence très variés, ce qui impose de réviser certaines méthodologies si elles doivent être appliquées au mécanisme de l'article 6.4. Le document étudie aussi les avantages et les implications de la participation au mécanisme de l'article 6.4 des Parties hôtes, laquelle peut avoir des incidences sur l'exécution de leurs CDN.

Classifications JEL: F53, Q54, Q56, Q58

Mots-clés : CCNUCC, marchés du carbone, Accord de Paris, Article 6, Protocole de Kyoto, niveaux d'émissions de référence, MDP 


\section{Table of Contents}

Foreword 2

Acknowledgments 3

Abstract 4

Résumé $\quad 4$

$\begin{array}{ll}\text { List of acronyms } & 7\end{array}$

Executive Summary 9

1 Introduction 12

2 How is the Article 6.4 mechanism different to the Kyoto Protocol mechanisms? 14

A brief recap of the CDM and JI 15

Key differences between the Article 6.4 mechanism and the Kyoto Protocol's crediting
mechanisms

$\begin{array}{ll}\text { Process implications } & 20\end{array}$

3 Baseline methodological approaches under consideration for Article 6.4 21

Baseline methodological approaches in the current negotiation text: analysis of potential implications

$\begin{array}{lr}\text { A "performance-based" approach } & 23\end{array}$

$\begin{array}{ll}\text { A "best available" approach } & 23\end{array}$

Sub-bulleted conditions to be taken into account for the application of the "performancebased" approach or the "best available" approach 23

An approach based on "business as usual" emissions 26

$\begin{array}{ll}\text { An approach based on historic emissions } & 26\end{array}$

Implications for Article 6.4 baseline methodologies, approaches and assumptions 26

4 Deep dives on the implications of different baseline methodologies for two sectors 29

Power generation sector (i.e. supply side) 29

Why might power generation mitigation activities be important for Article 6.4 mechanism? $\quad 29$

Evaluation of the current methodological baselines tools under the CDM for grid-connected power plants: the Combined Margin methodological tool 30

Implications for setting baselines under Article 6.4 32 
Cement sector: Reduction of clinker share in blended cement 33

Why might the cement-related mitigation activities be important for Article 6.4? 33

Evaluation of current methodological approaches under the CDM for blending-type activities 36

Implications for setting baselines under Article 6.4

6 Conclusions $\quad 44$

$\begin{array}{ll}\text { References } & 47\end{array}$

$\begin{array}{ll}\text { Annex A } & 52\end{array}$

\section{Tables}

Table 1. Possible options for Article 6.4 to support increased ambition of future pledges 18

Table 2. Analysis of baseline methodological approaches and bulleted conditions 28

Table 3. Pros and cons of using different baseline methodological approaches for cement blending-type
activities

Table 4. Examples of variation of CM emission factor values used in CDM activities in CDM host countries 53

\section{Figures}

Figure 1. Potential impact of transferring emissions internationally under CDM and Article 6.4 on a host Party's accounted emissions in the presence of a corresponding adjustment

Figure 2. The most used methodologies for registered CDM activities and for CERs issued

Figure 3. Examples of variation of maximum and minimum CM emission factor values used in CDM activities

in some CDM host countries electricity grids

Figure 4. Different stages of cement production, and associated emissions

Figure 5. Number of registered activities and issued CERs per CDM methodology relevant to the cement sector

Figure 6. A marginal abatement curve of a hypothetical country, illustrating the potential cost impact of internationally transferring credits from different types of activities

\section{Boxes}

Box 1. Crediting mechanisms' baselines and the principle of conservativeness 19

Box 2. Challenges in fitting project baselines in the NDC context 25

Box 3. Why does clinker production involve high $\mathrm{CO}_{2}$ emissions? 


\section{List of acronyms}

AIXG Annex I Expert Group

A6.4 Article 6.4 mechanism

A6.4ER Article 6, paragraph 4, emission reduction

BM Build Margin

BURs Biennial Update Reports

CCGT Combined cycle gas turbine

CDM Clean Development Mechanism

CDM EB CDM Executive Board

CERs Certified Emission Reductions

CM Combined Margin

CMA Conference of the Parties serving as the meeting of the Parties to the Paris Agreement

COP Conference of the Parties to the UNFCCC

ERs Emission Reductions

ERUs Emission Reduction Units

GHG Greenhouse gases

GNR Getting the Numbers Right

JI Joint Implementation

JISC Joint Implementation Supervisory Committee

IET International Emission Trading 
ITMOs Internationally transferred mitigation outcomes

IRR Internal Rate of Return

KP Kyoto Protocol

MRV Monitoring, reporting and verification

NDCs Nationally Determined Contributions

OCGT Open cycle gas turbine

OM Operating Margin

OMGE Overall Mitigation in Global Emissions

PoA Programme of activities

RTS Reference Technology Scenario

SBSTA Subsidiary Body for Scientific and Technological Advice

SD Sustainable Development

UNFCCC United Nations Framework Convention on Climate Change 


\section{Executive Summary}

Article 6.4 of the Paris Agreement establishes a mechanism to "contribute to the mitigation of greenhouse gas emissions and support sustainable development" (UNFCCC, 2016 $\left.{ }_{[1]}\right)$. A decision on the provisions for Article 6 is due by the $25^{\text {th }}$ Conference of the Parties (COP) to the United Nations Framework Convention on Climate Change (UNFCCC) in December 2019. One topic under discussion is methodological approaches for setting emissions baselines for the Article 6.4 mechanism. An emissions baseline sets the reference level against which the number of emissions reductions is calculated. Different approaches, methodologies and assumptions can be used to determine an emissions baseline. ${ }^{1}$ The methodologies used to establish emissions baselines will determine the maximum number of credits that can be generated by Article 6.4 activities. Baseline methodologies thus affect the impact of the Article 6.4 mechanism on mitigation, the attractiveness of participating in the mechanism, as well as inter alia the role of the mechanism in supporting Parties in meeting their Nationally Determined Contributions (NDCs), and the cost of doing so. This paper examines options currently under discussion for baseline approaches for the Article 6.4 mechanism, and draws lessons from how baselines have been used for other market mechanisms.

The international community already has experience of market-based mechanisms for emission reductions, including under the UNFCCC's Kyoto Protocol (KP). However, the Paris Agreement provides a new context. In particular, all host Parties participating in the new mechanism will have an NDC with mitigation pledges, whereas host countries under the KP's Clean Development Mechanism (CDM) were not accountable for their greenhouse gas (GHG) emissions. This may mean that host Parties need to pursue a different, and potentially more stringent, approach to authorising credit transfers under Article 6.4 than they did under the CDM. Further elements that differ from the KP are that the Article 6.4 mechanism is to deliver "overall mitigation in global emissions" (OMGE) and that Article 6 overall explicitly aims to encourage higher ambition in Parties' mitigation and adaptation actions. However, both the current draft negotiation text for Article 6.4 mechanism methodologies and the CDM share the principle that baselines are to be "conservative".

A one-size-fits-all approach to setting baselines is unlikely to be appropriate for the new mechanism, given the diversity of possible mitigation activity types and contexts. Indeed, the draft negotiation text from June 2019 (UNFCCC, 2019[2]) leaves open a wide variety of possible approaches to determine emissions baselines for the Article 6.4 mechanism. Among these approaches (all of which would need further clarification in order to be operationalised), the following are assessed in this paper: (i) a "performancebased" approach (that estimates the GHG emission reductions of an activity against peers by providing an

\footnotetext{
${ }^{1}$ This paper uses the term baseline "approaches" to refer to the way that baselines are established (e.g. in line with historic emissions). An approach can be applied in multiple different ways, laid out in baseline "methodologies" (e.g. for the case of an approach based on "historic emissions", the baseline could be the annual average of the latest ' $x$ ' years of the activity's emissions). Within methodologies, different assumptions (such as the value of ' $x$ ', choice of project boundary etc.) can also affect the level of an emissions baseline.
} 
emission reference level), (ii) a "best available" approach (potentially a variant of the "performance-based" approach, considering the "best available technology" or process), (iii) a "business as usual" (BAU) approach (that creates a forward-looking scenario describing how GHG emissions may progress in the absence of the mitigation activity) and (iv) an approach based on "historic emissions" (that extrapolates future emissions based on historical performance). Further approaches mentioned in the current draft negotiation text are not specific enough to allow for detailed analysis in this paper.

Each of the approaches for determining baselines discussed in this paper presents advantages and disadvantages regarding its use in the context of Article 6.4. For instance, the "performance-based" approach is relatively straightforward to apply, although may rely on subjective choices in order to establish a baseline. A crediting approach based on "historic emissions" is relatively straightforward to establish, but is unlikely to lead to a path consistent with the Paris Agreement goals, as analyses of current levels of emissions and expected emissions pathways indicate. Development of BAU scenarios can be more conservative than baselines based on historical emissions, but can be subjective, given the range of plausible assumptions, and may therefore include significant uncertainty.

Two "deep dives" done for this paper, one on grid-connected power plants and one on blending-type activities in the cement sector ${ }^{2}$, analyse existing methodologies and methodological tools under the CDM and highlight some of the implications of setting baselines in these sectors under Article 6.4. The analysis shows that a single approach - and even a single methodological tool - can lead to very wide variations in baseline levels, depending on the particular methodologies and assumptions chosen.

In particular, the most commonly-used methodological tool under the CDM - for grid-connected power plants - has led to baselines for this project type varying by more than a factor of two within a given electricity grid in a given country (including China, India, Peru, the United Arab Emirates), and by up to a factor of seven in one country (Brazil) over a short timeframe. This "combined margin" (CM) methodological tool, a type of performance-based approach used to calculate the baseline levels for grid-connected power plants, was designed to estimate the GHG intensity of electricity being displaced by particular projects. Some variation in baseline level between different countries and electricity grids, as well as within a given country and electricity grid, is to be expected. However, such large variations within a single baseline approach, as shown in the power sector deep dive - including instances where project baselines were set at the level of an inefficient gas-fired plant despite being connected to grids dominated by hydropower raise questions over what can be considered as "conservative" under the Paris Agreement. This variation in baseline levels from a single approach also highlights the crucial role that detailed methodologies and assumptions have in determining baseline and crediting levels.

In contrast, the cement sector deep-dive suggests that fewer changes might be needed if the CDM methodology agreed for blending-type activities in the cement sector were to apply to the Article 6.4 mechanism. This is because the current CDM methodology uses a dynamic benchmark approach for the baseline clinker-to-cement ratio (a type of "performance-based" approach) that can be considered as a conservative baseline. CDM methodologies such as ACM0005 however mainly address supply-side emission reductions whereas opportunities to reduce emissions on the demand-side exist as well. Future work could be beneficial to understand whether and how the Article 6.4 mechanism could facilitate transformative changes in high-emitting sectors such as cement by encompassing mitigation activities focused on the demand-side.

This analysis implies that a rigorous technical assessment of baseline methodologies and assumptions used in developing emissions baselines will be important for the Article 6.4 process. It would therefore be

\footnotetext{
2 Blending-type activities refer to the production of blended cement that reduces the share of clinker (a high GHGemitting material input in cement production) by combining it with lower GHG-emitting additives.
} 
useful if the framework for Article 6.4 to be agreed at COP25 provides a mandate for the Supervisory Body or associated technical experts to carry out such an assessment - or implement other safeguards. This could help to ensure that Article 6.4 emissions baselines and their underlying methods and assumptions are conservative, including the potential use of existing CDM methodologies or methodological tools in Article 6.4

Baseline-setting can also have important implications for Parties hosting Article 6.4 activities, in particular for how transfers of Article 6.4 emission reductions affect achievement of NDCs. For example, an inflated emissions baseline would produce credits for which there have been no associated emission reductions (raising concerns about environmental integrity). Such a baseline could also mean that the host Party will need to undertake further mitigation efforts to achieve their NDC, if a "corresponding adjustment" is made for all such international transfers. Host Parties may need to consider whether and which abatement options in the short-, medium- and long-term they will retain for domestic use, and which could be used to generate credits under the Article 6.4 mechanism for international transfer. For example, host Parties could consider voluntarily setting limits during the authorisation process for an Article 6.4 activity on the number of credits to be internationally transferred from that activity in a given time period.

Finally, the conditionality of many Parties' NDCs means that the level of a conservative emissions baseline can potentially be affected by the receipt of international climate finance. Potential updates to baseline levels following provision of support (by ensuring, for instance, that baseline levels are dynamic, i.e. that they can change during the crediting period) is another important consideration for the Article 6 rules. 


\section{Introduction}

International market-based mechanisms can represent cost-effective policy instruments for greenhouse gas (GHG) mitigation. Article 6 of the Paris Agreement establishes two market-based paths for Parties to voluntarily co-operate "in the implementation of their nationally determined contributions (NDCs) to allow for higher ambition in their mitigation and adaptation actions and to promote sustainable development and environmental integrity" (UNFCCC, 2016 $\left.{ }_{[1]}\right)$. The principles for voluntary co-operative approaches involving the use of internationally transferred mitigation outcomes (ITMOs) towards NDCs are set out in Article 6.2. Article 6.4 establishes a mechanism to contribute to the mitigation of GHG emissions and support sustainable development. This mechanism will operate "under the authority and guidance of the Conference of the Parties serving as the meeting of the Parties to the Paris Agreement" (UNFCCC, 2016[1]). After being postponed from the Conference of the Parties to the United Nations Framework Convention on Climate Change (UNFCCC) in December 2018 (COP24), a decision on the provisions for Article 6 is due by COP25 in December 2019.

To support the design of the Article 6.4 mechanism, the aim of this paper is to provide a technical examination of selected approaches currently under discussion in Article 6.4 negotiations for setting emissions baselines for the mechanism. These emissions baselines will set the reference level of GHG emissions against which the maximum amount of Article 6.4 credits that can be issued is calculated. ${ }^{3}$ Although not specifically described as such, the Article 6.4 mechanism is widely understood to be designed as a crediting mechanism ${ }^{4}$, i.e. where credits are awarded ex post if the actual emissions are below a predetermined baseline level. Baseline methodologies will therefore be used to determine the crediting level of the activities of the mechanism, i.e. to quantify the emission reductions resulting from a GHG mitigation activity and to calculate the associated credits, called "Article 6.4 Emission Reductions" (A6.4ERs). Methodological approaches for setting emissions baselines have been discussed extensively in the literature, especially in the context of the KP mechanisms, e.g. including in previous $\mathrm{CCXG}^{5}$ papers, see (Ellis and Bosi, 2000[3]; Willems, 2001[4]; Violette, Mudd and Keneipp, 2001[5]; Salon, 2001[6]; Ellis, 2001 [7];

\footnotetext{
3 This paper uses the term baseline "approaches" to refer to the way that baselines are established (e.g. in line with historic emissions). An approach can be applied in multiple different ways, laid out in baseline "methodologies" (e.g. for the case of an approach based on "historic emissions", the baseline could be the annual average of the latest ' $x$ ' years of the activity's emissions). Within methodologies, different assumptions (such as the value of ' $x$ ', choice of project boundary etc.) can also affect the level of an emissions baseline.

4 The Paris Agreement and its accompanying decision (1/CP.21) do not explicitly state whether the Article 6.4 mechanism will be a crediting mechanism or a trading mechanism (i.e. where a fixed emission cap is set and tradable allowances are issued ex ante). However, the references to the concept of "additionality" and to "crediting periods" in the latest draft negotiation text (UNFCCC, 2019 [2] $)$ imply that the Article 6.4 mechanism is being designed as a crediting mechanism, as it is also widely reported in the literature see e.g. (Marcu, 2016[36]; Gao et al., 2019[37]; Schneider et al., 2018[18]; Michaelowa et al., 2019[38]). The analysis presented in this paper considers the Article 6.4 mechanism as a crediting mechanism based on specific activities or projects, rather than sector-wide crediting. For deeper analyses on the distinction between crediting and trading mechanisms, please refer for instance to (Prag and Briner, 2012 [11]) and (Schneider, Fuessler and Herren, 2014[19]).

${ }^{5}$ Prior to 2009, the OECD/IEA Climate Change Expert Group (CCXG) was called the Annex I Expert Group (AIXG).
} 
Bosi, 2001[8]; Kartha, Lazarus and Bosi, 2002[9]; Bosi and Laurence, 2002[10]; Prag and Briner, 2012[11]; Clapp and Prag, 2012[12]).

In the UNFCCC context, baseline approaches were initially elaborated under the two crediting mechanisms of the Kyoto Protocol (KP): the Clean Development Mechanism (CDM) and Joint Implementation (JI). A large number of baseline methodologies have since been developed under these approaches. As the Article 6.4 mechanism will operate in the context of the Paris Agreement, it is timely to assess whether and how the baseline approaches and methodological tools used in the KP mechanisms are applicable, and if any changes are required. Therefore, in designing Article 6.4, a better understanding of the different options currently under discussion for baseline approaches for the new mechanism, as well as of the methodologies developed under the CDM and $\mathrm{JI}$, is needed. The paper also assesses the experience with selected CDM baseline methodologies and methodological tools in two sub-sectors, to identify possible lessons relevant for Article 6.4. Moreover, the paper analyses environmental implications for host Parties participating in the mechanism. Further implications on baseline approaches, such as on governance, are outside the scope of this paper. Other elements of the design and operation of the new mechanism will naturally also affect the eligibility of particular activities and how many credits are issued. These include, among others, boundary setting, whether any additionality testing will be used (e.g. through a financial test or activity eligibility list or other) and whether or how a "corresponding adjustment" would be carried out for Article 6.4 units internationally transferred and/or used. In the interests of brevity, this paper focuses in particular on baselines issues, while recognising the importance and potentially interrelated nature of other design elements.

This paper is structured as follows. Section 2 provides an overview of the differences between KP mechanisms and Article 6.4. Section 3 analyses the implications of the selected current proposals for baseline methodological approaches for Article 6.4. Section 4 analyses existing methodologies and methodological tools under the CDM for grid-connected power plants in the power generation sector and for blending-type activities in the cement sector, and highlights the implications of setting baselines for these activities under Article 6.4. Section 5 outlines the potential benefits and implications for host Parties engaging in Article 6.4. Section 6 presents conclusions. 


\section{How is the Article 6.4 mechanism different to the Kyoto Protocol mechanisms?}

The concept of using GHG emissions crediting mechanisms to maximise cost-effectiveness of emissions mitigation and therefore to encourage increased ambition was first established in the UNFCCC context as part of the Kyoto Protocol (KP) (UNFCCC, 1998[13]). This Protocol, agreed in 1997, established two crediting mechanisms: the Clean Development Mechanism (CDM) and Joint Implementation (JI). ${ }^{6}$ The CDM allowed emission reductions from registered activities in "non-Annex I" countries to be transferred to "Annex I" countries ${ }^{7}$, who could use these credits for compliance with their emissions commitments under the KP. Jl allowed emission reductions from registered activities ${ }^{8}$ to be transferred and acquired within Annex I countries.

The mechanism established under Article 6.4 of the Paris Agreement shares some key characteristics with the CDM and $\mathrm{JI}$. In particular, participation in the Article 6.4 mechanism is voluntary, provides for increased cost-effectiveness in global GHG emissions mitigation via transfer of credits between different countries, and is subject to international oversight. ${ }^{9}$ In addition, the Paris Decision indicates that the rules for the Article 6.4 mechanism are to be on the basis of ensuring "real, measurable and long-term" benefits, as was the case for the CDM (UNFCCC, 2016[1] ; UNFCCC, 1998[13]). There are also some key differences, including that the Article 6.4 mechanism aims to deliver "Overall Mitigation in Global Emissions" (OMGE) and to encourage higher ambition in Parties' mitigation and adaptation actions. Further, there is a different context for host Parties under the Article 6.4 mechanism compared to host Parties under the CDM. Indeed, all host Parties will (by definition, if they are Parties to the Paris Agreement) have an NDC, whereas host countries under the CDM were not accountable for their emissions under the Kyoto Protocol. This section provides an overview of the main differences between Article 6.4 and the KP crediting mechanisms.

\footnotetext{
${ }^{6}$ A third KP mechanism, International Emissions Trading (IET), is a trading mechanism and is therefore not further analysed in this paper.

7 "Annex I" Parties include the industrialised countries that were members of the OECD in 1992 plus some economies in transition, listed in the Annex I to the UNFCCC. "Non-Annex I" are all remaining countries (UNFCCC, 2019 [42]).

$8 \mathrm{JI}$ has two different procedures for projects involving trade among Annex I Parties: Track 1 and Track 2. Under Track 1 of $\mathrm{Jl}$ it is the host Party that governs the registration of activities, emission reductions and methodologies, without the international oversight of the UNFCCC. Track 2 of $\mathrm{JI}$ involves international oversight by an international body (the JI Supervisory Committee - JISC) which is in charge of approving activities, emission reductions and methodologies. In this context, under Track 1 of JI the terms "registered activities" means "approved by the host country".

${ }^{9}$ E.g. the CDM and Track 2 of $\mathrm{Jl}$ are also subject to international oversight.
} 


\section{A brief recap of the CDM and JI}

The CDM and $\mathrm{Jl}$ were conceived as offsetting mechanisms: a purchasing (acquiring) Party can use the entirety of the credits resulting from the emissions reduced by a project or programme in a host Party to offset the same level of domestic emissions. Under the KP, during the first commitment period (2008-2012) only a subset of Parties (Annex B countries) ${ }^{10}$ had emissions mitigation commitments, and in the second commitment period (2013-2020) only a subset of Annex B countries have mitigation commitments. In particular, the CDM allows Annex B Parties to offset their emissions by purchasing Certified Emission Reductions (CERs) issued by activities based in Non-Annex I Parties (host Parties). Jl allows Annex B Parties to offset their emissions by purchasing Emission Reduction Units (ERUs) generated by mitigation activities in other Annex B countries, with the exchange accounted for under the KP targets of both countries. A key difference between $\mathrm{JI}$ and the CDM is that host Parties participating in $\mathrm{JI}$ (Annex B countries) have national emissions mitigation commitments to the Convention, while host Parties participating in the CDM (Non-Annex I Parties) do not.

The KP crediting mechanisms in theory allow a predetermined GHG emission mitigation target to be met more cost-effectively. Thus, the purchasing Party would acquire credits issued from the emissions reduced by an activity in a host Party that could be significantly cheaper than reducing the same level of emissions domestically. With all credits generated being able to offset emissions elsewhere, the overall effect of $\mathrm{Jl}$ in terms of absolute global GHG emissions is a zero-sum game (as both the purchasing and transferring Parties have mitigation commitments). The CDM does not necessarily lead to absolute reductions in global GHG emissions (albeit a reduction in emissions at the activity level compared to the baseline situation in the absence of the CDM activity), because emission credits in one country are not offset by emissions debits in another.

\section{Key differences between the Article 6.4 mechanism and the Kyoto Protocol's crediting mechanisms}

The key differences in context and aims between the Article 6.4 mechanism compared to CDM and $\mathrm{JI}$ are:

- Context: all Parties participating in the Article 6.4 mechanism will have mitigation pledges, whereas only the purchasing (acquiring) Parties participating in CDM had such targets. This may mean that host Parties need to pursue a different approach to approving activities and authorising credit transfers under Article 6.4 than they did under the CDM.

- Aims:

- The Article 6.4 mechanism is to deliver "Overall Mitigation in Global Emissions" (OMGE). This did not occur in $\mathrm{JI}$ (which was a "zero-sum game"), nor was it a requirement in the CDM.

- Article 6 explicitly aims to encourage higher ambition in Parties' mitigation and adaptation actions.

\footnotetext{
${ }^{10}$ Countries in the "Annex B" of the KP comprise Annex I Parties to the UNFCCC and some economies in transition: Australia, Austria, Belgium, Bulgaria, Canada, Croatia, Czech Republic, Denmark, Estonia, European Community, Finland, France, Germany, Greece, Hungary, Iceland, Ireland, Italy, Japan, Latvia, Liechtenstein, Lithuania, Luxembourg, Monaco, Netherlands, New Zealand, Norway, Poland, Portugal, Romania, Russian Federation, Slovakia, Slovenia, Spain, Sweden, Switzerland, Ukraine, United Kingdom of Great Britain and Northern Ireland, United States of America.
} 
Regarding the differing context, under the KP non-Annex I Parties could approve the issuance of credits from CDM activities without any potential disbenefit nor cost. In contrast, in the context of the Paris Agreement, if a host Party authorises an international transfer of credits, a corresponding adjustment could potentially be applied to the host Party's emissions. ${ }^{11}$ Figure 1 highlights that if host Parties are required to undertake corresponding adjustments to account for any credits generated under Article 6.4 of the Paris Agreement and transferred internationally, it will increase accounted emissions (i.e. the emissions level relevant for tracking NDC progress) and thus accounted emissions would exceed emission levels reported in the national GHG inventory, with potential consequences on the host country's ability to meet its NDC target. ${ }^{12}$ Hosting Article 6.4 activities can bring benefits to the host country, such as, inter alia, encouraging investment in the underlying activity (and associated outputs), and increasing local employment. These benefits, as well as the impact on host Parties participating in Article 6.4 activities, are discussed further in Section 5 .

Figure 1. Potential impact of transferring emissions internationally under CDM and Article 6.4 on a host Party's accounted emissions in the presence of a corresponding adjustment

CDM

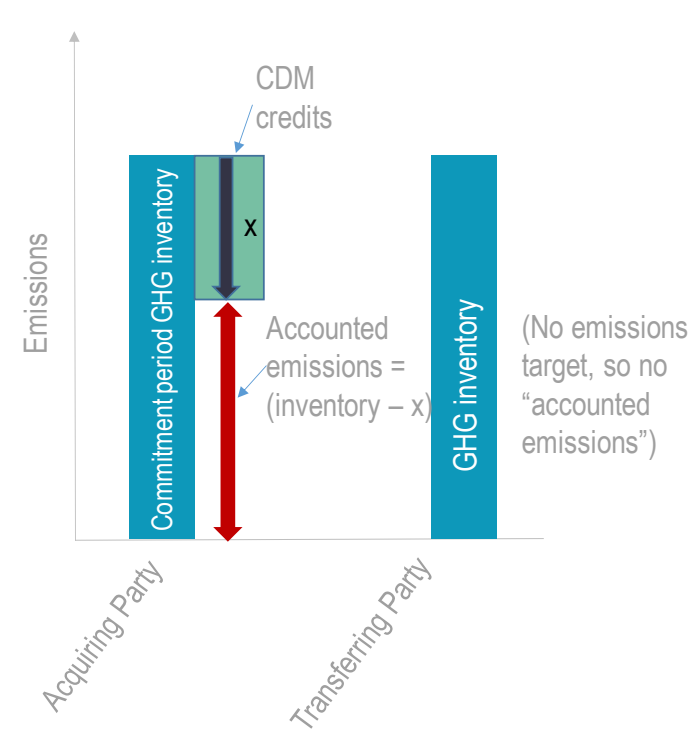

Article 6.4 mechanism

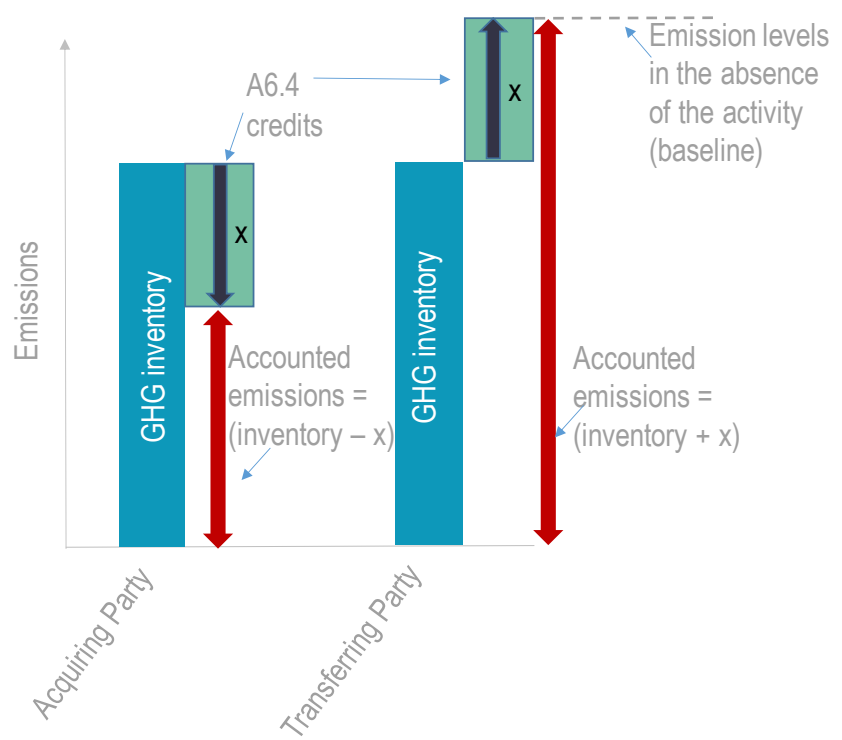

Note: It is not yet clear whether and how a corresponding adjustment could be potentially applied for transfers under the Article 6.4 mechanism. The figure assumes an international transfer of A6.4ERs and an application of a corresponding adjustment on that transfer. The exact amount of emissions to be correspondingly adjusted depends on the acquiring and transferring Party's choice(s) of accounting methods see (Lo Re and Vaidyula, $\left.2019_{[14]}\right)$. The figure also assumes that credits are used in the year they are generated. For the CDM the figure is illustrative as under the Kyoto Protocol emissions were accounted for using a stock of units including CERs rather than an accounting balance. The figure uses the term "accounted emissions" to mean the level of a Party's emissions that correspond to accounting for its mitigation target. GHG = greenhouse gases.

Source: Authors.

\footnotetext{
${ }^{11}$ It is not clear yet whether and how a corresponding adjustment could be applied for transfer under the Article 6.4 mechanism.

12 In reality, emission reductions from individual Article 6.4 activities may not be of a sufficient scale to make a visible impact on the GHG inventory of the host Party. Nevertheless, the principle described here remains important for the integrity of the mechanism.
} 
In terms of differences in aims, in the context of Article 6.4 the concept of OMGE and its operationalisation have not yet been clearly defined. There are currently different interpretations of this concept and how it could be achieved. OMGE could potentially impact Article 6.4 baselines in two ways - either via their crediting levels (as reflected in the current draft negotiation text), and/or via the length of time for which an activity can generate credits (not currently included in the draft text). ${ }^{13}$ The issue of baselines, crediting periods and OMGE are therefore interlinked, but a detailed discussion on this topic is beyond the scope of this paper.

A second reason that the aims of Article 6.4 differ from those of KP mechanisms is because Article 6 is explicitly intended to provide an avenue to increase ambition of future pledges. ${ }^{14}$ This is important because the current set of NDCs is not sufficiently ambitious to reach the global goals of the Paris Agreement (International Energy Agency, 2015 $[15]) .{ }^{15}$ However, it is not clear how Article 6.4 can increase the ambition of future pledges in practice. It is important to note that the Article 6.4 mechanism is not itself the driver of ambition, since that comes from the progression in NDC ambition over time. Nonetheless, there are different possible means to potentially increase the ambition of future pledges, and these vary in terms of their political and technical feasibility. The framework for Article 6.4 could be set up in a variety of ways to increase the ambition of future pledges, e.g. encouraging the development of transformational activities (rather than incremental improvements in existing activities), discouraging participation in Article 6.4 of specific types of activities, ensuring that using rules relating to baselines, credits and/or crediting periods limit crediting levels from authorised activities, limiting perverse incentives for countries not to increase the ambition of their NDCs if this will reduce the level of crediting possible from Article 6.4 activities. These are outlined in Table 1 below.

\footnotetext{
13 Some of the options currently discussed to deliver OMGE include voluntary cancellation, the application of conservative baselines or baselines "below business-as-usual" levels, the application of default conservative emission factors, the transfer of a discounted volume of A6.4ERs, and the application of a corresponding adjustment on the amount of issued A6.4ERs to be transferred. It has also been suggested that the availability of the mechanism itself could be considered to deliver OMGE (UNFCCC, 2019[2]).

14 Articles 3 and 4 of the Paris Agreement define the progression and ambition infrastructure for NDC cycles, mandating for increased NDC ambition over time. The accompanying decision of the Paris Agreement (Decision 1/CP.21) invites Parties to communicate new NDCs by 2020 and to do so every five years thereafter. Article 4.2 requires ("shall") Parties to "pursue domestic mitigation measures" to achieve their NDC mitigation objectives.

${ }^{15}$ The IEA estimates that current NDCs will set the global temperature on a path consistent with about $2.6^{\circ} \mathrm{C}$ warming by 2100 , far from the "well-below $2^{\circ} \mathrm{C}$ " minimum objectives of the Paris Agreement.
} 
Table 1. Possible options for Article 6.4 to support increased ambition of future pledges

\begin{tabular}{|c|c|c|c|}
\hline Options & Description & Advantages & Challenges \\
\hline $\begin{array}{l}\text { Promote } \\
\text { transformational } \\
\text { change }\end{array}$ & $\begin{array}{l}\text { Use A6.4 to } \\
\text { encourage } \\
\text { "disruptive" } \\
\text { technologies/ } \\
\text { systems. }\end{array}$ & $\begin{array}{l}\text { Would enable significant improvements in GHG } \\
\text { emission reductions performance if A6.4 could } \\
\text { be used to focus on how to satisfy demand for a } \\
\text { particular service (e.g. food) more GHG- } \\
\text { efficiently, rather than focusing on improving } \\
\text { specific methods of producing a specific output } \\
\text { (e.g. cattle). }\end{array}$ & $\begin{array}{l}\text { May be more complex/data-intensive to set up } \\
\text { and agree internationally, if baseline methods } \\
\text { need international approval. Moreover it may be } \\
\text { more complex to set up also if it involves } \\
\text { establishing large boundaries around a particular } \\
\text { activity, including both supply and demand-side } \\
\text { information and data. }\end{array}$ \\
\hline $\begin{array}{l}\text { Discouraging } \\
\text { specific activity } \\
\text { types }\end{array}$ & $\begin{array}{l}\text { Establish eligibility or } \\
\text { other criterion at } \\
\text { international level to } \\
\text { discourage/ prohibit } \\
\text { specific types of } \\
\text { activity. }\end{array}$ & $\begin{array}{l}\text { Ensuring that a GHG-intensive means of } \\
\text { production for technologies with a long lifetime } \\
\text { and/or for which there are proven alternatives } \\
\text { (e.g. construction of new coal-fired power plants) } \\
\text { are not eligible for crediting under A6.4, could } \\
\text { discourage the construction of some GHG- } \\
\text { intensive technologies or systems. }\end{array}$ & $\begin{array}{l}\text { Setting rules at international level on the } \\
\text { eligibility (or not) of specific technologies or } \\
\text { processes may run counter to specific national } \\
\text { circumstances and Parties' ability to determine } \\
\text { what constitutes sustainable development. }\end{array}$ \\
\hline $\begin{array}{l}\text { Encouraging } \\
\text { specific activity } \\
\text { types }\end{array}$ & $\begin{array}{l}\text { Reduce barriers for } \\
\text { specific activity } \\
\text { types; e.g. lower } \\
\text { levels of international } \\
\text { oversight, any share } \\
\text { or proceeds, etc. }\end{array}$ & $\begin{array}{l}\text { Could encourage specific types of activities } \\
\text { which have a large total GHG mitigation } \\
\text { potential (e.g. energy efficiency activities, certain } \\
\text { small-scale activities) but where take-up has } \\
\text { been relatively low in carbon markets to date. }\end{array}$ & $\begin{array}{l}\text { Would need further discussion of how such } \\
\text { barriers could be reduced, and who would make } \\
\text { such decisions. It would also skew market } \\
\text { incentives. The idea of a "positive list" was not } \\
\text { politically palatable in the context of the CDM. }\end{array}$ \\
\hline $\begin{array}{l}\text { Limit crediting } \\
\text { levels (1) }\end{array}$ & $\begin{array}{l}\text { Lower the number of } \\
\text { credits generated by } \\
\text { a specific activity } \\
\text { compared to } \\
\text { calculated emission } \\
\text { reductions. }\end{array}$ & $\begin{array}{l}\text { Limiting the number of credits that could be } \\
\text { generated (e.g. via conservative baselines, short } \\
\text { crediting periods, and/or discounting of credits), } \\
\text { could raise their cost, which could in turn } \\
\text { encourage buyer countries to enhance their } \\
\text { efforts to reduce emissions domestically. }\end{array}$ & $\begin{array}{l}\text { Some countries have stated that their } \\
\text { current/future ambition is contingent on access } \\
\text { to international offsets. }\end{array}$ \\
\hline $\begin{array}{l}\text { Limit crediting } \\
\text { levels }(2)\end{array}$ & $\begin{array}{l}\text { Cap total levels of } \\
\text { credits generated by } \\
\text { the Article } 6.4 \\
\text { mechanism }\end{array}$ & $\begin{array}{l}\text { Would limit the extent to which buying countries } \\
\text { could limit/delay the introduction of measures to } \\
\text { reduce domestic emission levels. }\end{array}$ & $\begin{array}{l}\text { Would skew market incentives that A6.4 sets up, } \\
\text { would need ex ante rules e.g. on what the total } \\
\text { cap is. How a cap would influence crediting from } \\
\text { specific A6.4 activities such as discounting } \\
\text { credits from all activities, stopping approval of } \\
\text { proposed activities after a certain date/after a } \\
\text { certain threshold of activities and/or expected } \\
\text { emission reductions have been approved } \\
\text { internationally. }\end{array}$ \\
\hline $\begin{array}{l}\text { Increase sectoral } \\
\text { scope of non- } \\
\text { economy-wide } \\
\text { NDCs }\end{array}$ & $\begin{array}{l}\text { If the issuance of } \\
\text { A6.4ERs is allowed } \\
\text { for sectors outside of } \\
\text { current NDC scope, } \\
\text { require that the } \\
\text { sector is included } \\
\text { into the scope of the } \\
\text { next round of NDC. }\end{array}$ & $\begin{array}{l}\text { Would progressively increase the scope of the } \\
\text { NDC, encouraging early mitigation also in those } \\
\text { sectors that are currently not covered by the } \\
\text { NDC. }\end{array}$ & $\begin{array}{l}\text { Some countries might see this as a disincentive } \\
\text { to start early mitigation in sectors outside the } \\
\text { NDC scope if a corresponding adjustment is } \\
\text { required for transactions of ITMOs from outside } \\
\text { NDCs scope. }\end{array}$ \\
\hline $\begin{array}{l}\text { Limit perverse } \\
\text { incentives on } \\
\text { NDC ambition }\end{array}$ & $\begin{array}{l}\text { Ensure that the } \\
\text { ability to sell A6.4 } \\
\text { credits does not limit } \\
\text { the ambition of } \\
\text { Parties' current or } \\
\text { future NDCs. }\end{array}$ & $\begin{array}{l}\text { Would ensure that Parties' NDCs are of the } \\
\text { "highest possible ambition", rather than e.g. } \\
\text { medium-level ambition with buffer, allowing for } \\
\text { A6.4 credits to be sold and/or potential } \\
\text { corresponding adjustments to be made. }\end{array}$ & $\begin{array}{l}\text { Its implementation could pose challenges, as it } \\
\text { would involve assessment by a body other than } \\
\text { the Party on the level of ambition of its NDC. }\end{array}$ \\
\hline
\end{tabular}

Note: A6.4 = Article 6.4.

Source: Authors. 
As outlined in Table 1, one way of ensuring that Article 6.4 could increase the ambition of future NDCs is to limit crediting levels through conservative baselines, short crediting periods and/or discounting of credits. Two of these ways of limiting crediting levels (conservative baselines, potentially short crediting periods) were also applied to various extents in the CDM. The issue of discounting ${ }^{16}$ was discussed but not brought forward as a way to increase ambition under the CDM, see e.g. (Chung, 2007 [16]; Warnecke et al., 2014[17]; Schneider et al., 2018$\left.{ }_{[18]}\right)$. The concept of conservative baselines is introduced in Box 1.

\section{Box 1. Crediting mechanisms' baselines and the principle of conservativeness}

In a crediting mechanism, a baseline scenario is a depiction of how emissions would be likely to evolve in the absence of the mitigation activity, and is necessarily based on a set of assumptions (e.g. related to economic conditions, policy implementation, technology availability, etc.; see for instance (Ellis and Bosi, 2000[3]; Willems, 2001[4]; Violette, Mudd and Keneipp, 2001 ${ }_{[5]}$; Salon, 2001[6]; Ellis, 2001 [7]; Bosi, 2001 [8]; Kartha, Lazarus and Bosi, 2002[9]; Bosi and Laurence, 2002[10]; Prag and Briner, 2012[11]; Clapp and Prag, 2012[12]). The baseline sets the reference level of GHG emissions against which the amount of credits that can be issued is calculated. The emission level of the implemented mitigation activity, monitored ex post, is subtracted from the baseline level to obtain the number of credits. The assumption behind this calculation is that one credit equals to one tonne of carbon dioxide equivalent that has been reduced. If the actual GHG emissions level of the implemented mitigation activity is equal or higher than the baseline, no crediting is possible from that activity. The assumptions used to create any baseline scenario mean that there is inherent uncertainty, that if not addressed properly, can lead to missed mitigation opportunities or over-crediting in the mechanism (Schneider, Fuessler and Herren, 2014[19]).

According to Decision 17/CP.7 (UNFCCC, 2002[20]), CDM baseline scenarios were to be established in a conservative manner, reflecting GHG emissions that would have occurred in the absence of the CDM activity. In theory, this was meant to ensure that the level of credits issued were lower than the level of emission reductions achieved. In practice, there are often a variety of plausible assumptions that could be made regarding the development of a specific activity, leading to a variety of different baseline levels. Thus, even with detailed information on the specific activity and its context, it is difficult to assess whether the assumptions made were conservative. This means that establishing emissions baselines is inherently uncertain (i.e. there is a range of likely baseline scenarios). There is also therefore likely to be a range of possible "conservative" baselines. This will also be the case for baselines established under Article 6.4 of the Paris Agreement.

Another way that baselines could encourage greater ambition is to draw broad boundaries around an activity (e.g. encompassing both the demand-side as well as supply-side), rather than narrow supply-side boundaries as has often been the case under the CDM. For example, reducing emissions associated with manure management of cattle (a project type under the CDM) could be achieved by changes on the supplyside. However, focusing solely on the supply-side does not encourage the uptake of activities to improve the efficiency of the demand-side (e.g. by reducing food waste), even if this may be cheaper, quicker and reduce a greater level of emissions. Nevertheless, there are practical drawbacks in establishing wide boundaries, including requiring much more data to develop a baseline, as well as being more complex to monitor.

\footnotetext{
16 The term "discounting" in a crediting mechanism refers to multiplying by a discount factor (between 0 and 1 ) the number of credits issued. Considering that one credit corresponds to one tonne of GHG reduced, discounting could be seen as if the credits issued would count as less than one metric tonne of GHG reduced (Kollmuss and Lazarus, $2011_{[39]}$ ), or as if a fraction of the credits that are issued by the mechanism are set aside and not used. For an analysis on OMGE and discounting, please refer for instance to (Schneider et al., 2018[18]).
} 


\section{Process implications}

When designing the rules for the Article 6.4 mechanism, Parties may also wish to consider lessons learned from the KP for baseline methodology development and approval. The KP established international oversight for the CDM and "Track 2" of $\mathrm{Jl}$; whereas "Track 1" of $\mathrm{JI}$ was under the authority of the host country. The Article 6.4 mechanism is to be supervised by a body designated by the CMA (UNFCCC, $\left.2016_{[1]}\right)$. One important implication of this is on the potential application or not of "corresponding adjustments" on international transfers of A6.4ERs. If only some Parties involved in Article 6.4 transfers apply a "corresponding adjustment" to their accounted emissions, then the Supervisory Body of the Article 6.4 mechanism would need to apply particularly close oversight of Article 6.4 baseline approaches, methods and assumptions to maintain the environmental integrity of the mechanism.

Ensuring that the resources of the Article 6.4 Supervisory Body are used efficiently will be important, as is ensuring an efficient process of reviewing or approving Article 6.4 baselines. This could help to speed up the process of baseline approval for key activity types, which averaged approximately 10 months in the CDM. ${ }^{17}$ Some key lessons can be learned from the CDM in this regard. For example, the process that methodology developers needed to follow for all large-scale activities was identical, irrespective of whether a baseline was being developed for an activity type that was widely replicable (e.g. grid-connected renewables), or for an activity type that was likely to be much less replicated (e.g. energy efficiency improvements for a specific process). Two of the $250+$ approved CDM methodologies ${ }^{18}$ were used in more than $70 \%$ of activities and only a further six methodologies were used for more than $1 \%$ of CDM activities (see Figure 2). Even the tenth most used CDM methodology was used for fewer than $1 \%$ of activities. This means that much time and resources of the CDM Executive Board and its various panels were used on methodologies that were barely - sometimes never - used. In designing Article 6.4, Parties may want to consider if a similar development is desirable for the efficiency of the new mechanism.

\section{Figure 2. The most used methodologies for registered CDM activities and for CERs issued}
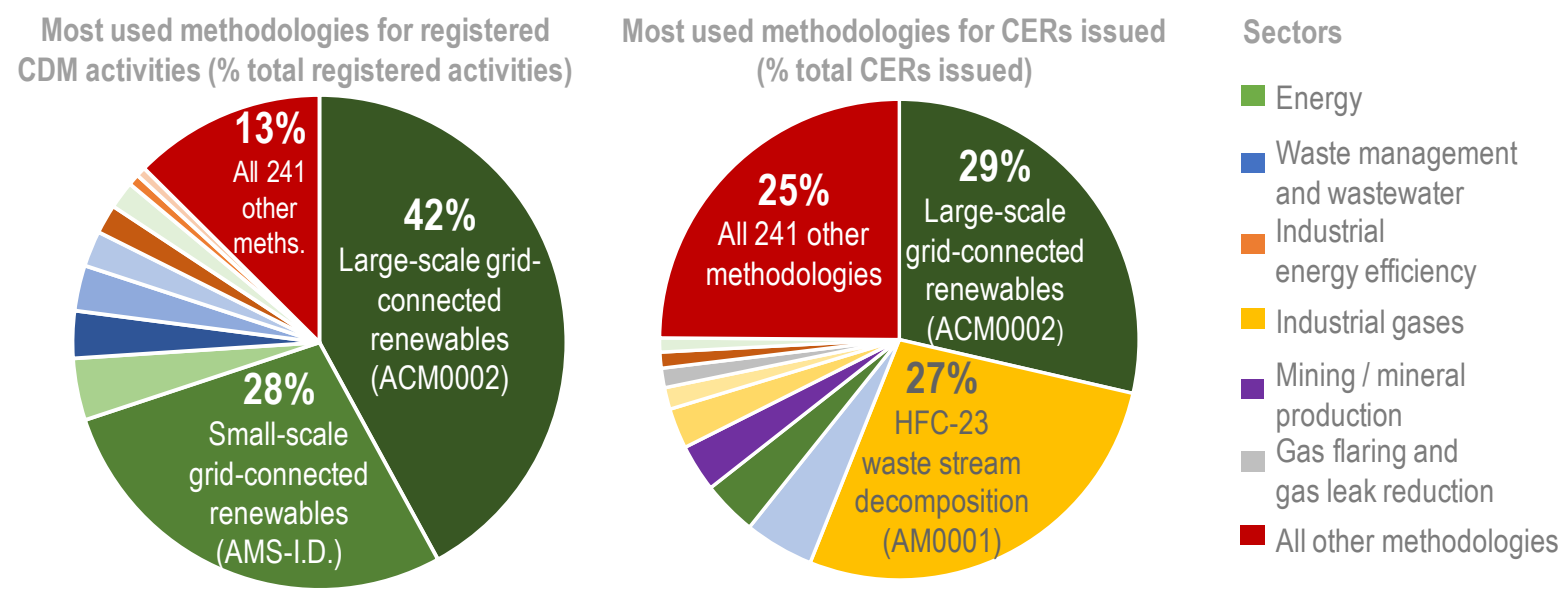

Source: Authors. Analysis with data from CDM Pipeline (as of July 2019).

\footnotetext{
17 The average time elapsed between the date of submission of a new large-scale methodology and its approval by the CDM Executive Board (CDM EB) is 311 days (UNEP DTU, 2019 $9_{[40]) .}$

18 ACM0002: Large scale grid-connected electricity generation from renewable sources; and AMS-I.D.: Small-scale grid connected renewable electricity generation.
} 


\section{Baseline methodological approaches under consideration for Article 6.4}

The current negotiation text does not yet clarify if eligible Article 6.4 activities would be limited to emission reductions, or would also include emission removals and emissions avoidance - and if so, what each term means (UNFCCC, 2019 ${ }_{[2]}$ ). The scope of this paper covers emission reductions as credited under the CDM (which actually includes emission reductions, as well as some types of emission removals and emissions avoidance $)^{19}$, and projects and programmes of activities for Article 6.4 (hereafter referred to as "activities"), recognising the potential need to develop new methodologies if the other emission categories are included.

Emission reduction activities undertaken under Article 6.4 of the Paris Agreement could potentially encompass a wide variety of mitigation actions, technologies and sectors. The rules currently being negotiated under Article 6.4 will therefore need to allow for a variety of different contexts, while also upholding specific principles, such as using conservative baselines and delivering overall mitigation, as outlined in Section 2. The current negotiation text provides for a choice in approaches and methods by which baselines can be calculated, to ensure that activity participants have the flexibility to use an approach and method that is relevant for their activity (UNFCCC, 2019 $[2]$ ).

The choice of baseline approach and methodology is important, as it is a key factor that affects the number of credits that can be generated by a specific activity. The approach used to develop an emissions baseline will also influence the extent to which credits are, inter alia, real and measurable. The requirement as laid out in the draft negotiation text that approaches, assumptions, parameters, data sources, key factors "shall" be conservative (paragraph 42; see (UNFCCC, 2019 ${ }_{[2]}$ ) will also affect the level of crediting from Article 6.4 activities. This section first outlines the implications and practicality of different options as proposed in the current draft text and highlights where text is difficult to interpret. It then highlights some considerations for the design of the baseline approaches for Article 6.4.

\footnotetext{
19 The CDM was able to generate emissions credits for projects that reduced absolute emissions (e.g. efficiency improvements at existing plants). The CDM also allowed emissions credits to be generated for some categories of emissions avoidance (e.g. for greenfield electricity plants, where the CDM activity results in emission levels lower than those that would have occurred in the absence of the CDM project activity, but potentially in equal or higher absolute GHG emission levels compared to pre-project activity levels). Other categories of emissions avoidance (e.g. avoided deforestation) were not eligible under the CDM. The CDM also allowed for credits to be generated by some types of emission removal activities (e.g. afforestation and reforestation).
} 


\section{Baseline methodological approaches in the current negotiation text: analysis of potential implications}

The current negotiation text (UNFCCC, 2019 ${ }_{[2]}$ ) contains a number of options that cover various permutations of different baseline approaches. These include:

- A "performance-based" approach;

- A "best available" approach;

- A discussion on the following sub-bulleted conditions, to be taken into account for the application of the "performance-based" approach or the "best available" approach:

- "Technologies that represent an economically feasible and environmentally attractive course of action"

○ "Barriers to investment";

- "A contribution to the reduction of the emission levels of the host Party";

- "The emissions pathway that would be consistent with the achievement of the NDC of the host Party";

- An approach based on "business as usual" emissions;

- An approach based on historic emissions.

However the options in the current negotiation text are not specific enough to indicate how exactly the proposed baseline approaches could be implemented in practice. The detailed methodologies, assumptions and parameters underlying an approach significantly impact the level of the baseline, and therefore its conservativeness and environmental integrity (this is explored for the particular case of the power generation sector in Section 4). Nevertheless, the different approaches in the negotiation text bring different advantages and challenges. This section highlights the potential range in environmental impacts of the following approaches listed in the negotiation text and summarises areas where implementing these options would require further clarity (UNFCCC, 2019 ${ }_{[2]}$ ).

Several factors important to the conservativeness of baselines are common to any of these possible methodological approaches. One such factor is the frequency of updating the baseline level. This is because the GHG emissions intensity of certain sectors could evolve substantially over time (Schneider, Fuessler and Herren, 2014[19]), including on receipt of international support for a country's climate actions. In such cases, it is important to ensure frequent updates to the baseline level (e.g. by ensuring that the baseline methodology is dynamic), otherwise there could be a risk of over-crediting.

Another factor common to most baseline approaches is to what extent the baseline levels can be standardised across activities, and if so, what the appropriate activity boundary is, and what scope there is for standardisation. The latest draft negotiation text mentions the possibility to develop "standardised baselines" for the Article 6.4 mechanism (UNFCCC, 2019[2] $)$. Some experience with standardised baselines has been gained through the CDM, which allowed the development of such baselines to help reduce transaction costs, enhance transparency, objectivity and predictability, and facilitate access to the CDM for underrepresented project types and regions (UNFCCC, 2011[21]), In the CDM, standardised baselines allowed the baseline level and the determination of additionality to be determined ex-ante for a group of similar CDM activities, rather than for each individual CDM activity. ${ }^{20}$ Whether to allow the development and use of standardised baselines in Article 6.4, and over what breadth and scope the

20 By November 2019, the CDM EB has approved 44 standardised methodologies (including 10 updated resubmissions) (UNFCCC, 2019[48]) 
baselines are standardised, could be an important further factor for implementation of the Article 6.4 mechanism, but is out of the scope of this paper.

\section{A "performance-based" approach}

The most common application of a "performance-based" approach in carbon markets is a performance benchmark baseline approach, which allows the estimation of the GHG emission reductions of an activity against peers by providing a reference emission level. The approach is most suited for those sectors where the outputs are homogeneous (e.g. power generation sector) (Schneider, Fuessler and Herren, 2014 [19]; Prag and Briner, 2012[11]). A GHG performance-related metric is often used (e.g. $\mathrm{tCO}_{2} \mathrm{e}$ per MWh for the power generation sector).

The reference level can be set in different ways, which can lead to differing benchmark stringency levels and would affect the conservativeness of the baseline and associated generation of credits. For example, the benchmark could be set at the "best achieved level" (most conservative), or "best available" level, average of top $\mathrm{X} \%$, average level or a hybrid model (e.g. average level of the $\mathrm{X}$ and $\mathrm{Y}$ percentile) (Partnership for Market Readiness (PMR), 2017[22]).

\section{A "best available" approach}

How the "best available" approach is defined will determine the range of technologies under consideration, and therefore the baseline level. , and so further clarity on this approach would be needed before its operationalisation. As for other approaches, "best available" could be defined in different ways.

One possible interpretation is that the "best available" approach is essentially a variant of a "performancebased" approach, considering the "best available technology" (BAT) or the best available process. This interpretation would require an assessment of the best-performing technology or process that can be reasonably expected to be applied for the activity and country in question. The "best available technology" (BAT) approach may lead to different baseline levels if a given technology is not available or applicable in a specific country or region. Therefore, the application of such an approach in country A can lead to a different baseline level than in country B. A given approach (such as BAT) could also lead to different baseline levels if the methodology used to calculate the baseline level used a single level for a "best available technology", or allowed for a range of levels (as a given technology can be used with different levels of GHG-efficiency). ${ }^{21}$ In such a case, the application of a given approach could lead to different baseline levels in a given country and sector, depending on the methodologies and assumptions used in such an approach.

\section{Sub-bulleted conditions to be taken into account for the application of the "performance-based" approach or the "best available" approach}

The current negotiation text (UNFCCC, 2019 $9_{[2]}$ ) also specifies some conditions to be taken into account in the applicability of the "performance-based" approach or the "best available" approach. It is unclear if the sub-bulleted conditions are stand-alone (i.e. would be considered one by one, either one or the other), or whether all the conditions need to be met simultaneously. Clarity on this matter could help to operationalise the approach and associated methods to be developed under it.

\footnotetext{
${ }^{21}$ For example, the efficiency of "clean coal" power stations can vary for a given technology (depending e.g. on the characteristics of fuel input as well as on temperature of cooling water), as can the level of HFC emissions from a specific technology used to manufacture aluminium.
} 
The sub-conditions mentioned in the text to be taken into account for the "performance-based" approach or the "best available" approach can be interpreted in several ways. ${ }^{22}$ For instance, "technologies that represent an economically feasible and environmentally attractive course of action" are likely to vary for different stakeholders. This would make "economically feasible" difficult to assess objectively, as what is economically feasible will be influenced by both site-specific (e.g. project location), and stakeholderspecific (e.g. ownership and financial situation - both of which may be confidential) information. In theory, an activity with a positive Internal Rate of Return (IRR) could be feasible, but not necessarily undertaken. The definition of "environmentally attractive" course of action is also not clear, as the text does not provide clarity whether it refers to GHG emissions only or more broadly to the wider environment.

"Barriers to investment" is mentioned as part of the conditions to be taken into account for the "performance-based" (or "best available") approach (UNFCCC, 2019 $\left.{ }_{[2]}\right)$. There is a degree of subjectivity inherent with this condition, as barriers to investment are specific to an individual activity context, depending inter alia on the economic characteristics of the entity seeking financing. This could lead to situations where there is information asymmetry between the activity promoters and the verifiers or the regulators (Schneider, Fuessler and Herren, 2014[199]).

The text also refers to the need for the "performance-based" (or "best available") approach to take into account "a contribution to the reduction of the emission levels of the host Party" (UNFCCC, 2019 ${ }_{[2]}$ ). This could be done in different ways, such as discounting; applying conservative baselines, approaches or assumptions; or limiting the crediting lifetime of an activity. Clarity on these details and if/how they link to conditions relating to OMGE, is needed in order to enable this condition to be operationalised.

The draft text also includes a possible condition relating to "the emissions pathway that would be consistent with the achievement of the NDC of the host Party" (UNFCCC, 2019[2]]). However, this condition would be difficult to implement in practice because most Parties' NDCs are established at a macro level (often nationwide), and do not contain information on expected emissions trends at the level needed for an Article 6.4 activity baseline (see Box 2).

\footnotetext{
${ }^{22}$ The sub-bulleted condition "the emissions of activities providing similar outputs and/or services in similar social, economic, environmental and technological circumstances" is not discussed in this paper.
} 


\section{Box 2. Challenges in fitting project baselines in the NDC context}

If the baseline used for each project activity could be perfectly aligned with the sectoral emission levels for the host country under its NDC, that would provide host Parties a clear means to demonstrate that credited activities go beyond the action needed to achieve the Party's NDC (in addition to just going beyond "business as usual"). However, establishing consistency between project baselines and a Party's NDC is not possible because of lack of data in the NDC. Moreover, even if the NDC contained information on sectoral emission levels, matching project and sector baselines can be technically challenging and can create perverse incentives related to enhancement of NDC ambition.

In practice, most Parties' NDCs are established at the national level and do not contain sufficient information on expected emissions trends at the disaggregation needed for an Article 6.4 activity baseline, such as at the sectoral, sub-sectoral or activity level. Trends in sector (and sub-sector) emissions can be very different from that of the Party as a whole. Explicitly linking emissions baselines to a Party's NDC level may also lead to perverse incentives for countries to not increase the ambition of their NDC as it would reduce the level of crediting possible from the Article 6.4 mechanism in the next NDC period.

Another issue is whether NDCs, even if they contain specific sectoral mitigation targets, should be taken as a guide for ambitious baselines. For some NDCs, taking expected NDC emission trends as a de facto baseline for an Article 6.4 activity could lock-in low ambition for the duration of the crediting period. Such lock-in of low ambition could be reduced by instigating a condition that if an activity baseline established through one of the allowed baseline approaches is shown to be more ambitious than a baseline implied by the NDC, then the former should be selected as the baseline. More generally, using the NDC as a basis for Article 6.4 baselines could be a perverse incentive preventing NDCs becoming more ambitious over time, as mandated by Article 4.3 of the Paris Agreement, depending on when and how baselines are updated.

Finally, the conditionality of NDCs can play also an important role, potentially affecting the level of baselines for projects and programmes in Article 6.4 and adding a further layer of complexity. More than 100 of the NDCs communicated to the UNFCCC to date include a "conditional" mitigation contribution alongside an "unconditional" contribution. The conditional part reflects the further contribution from a Party if it receives a given level of international support. The way that countries have calculated their support needs varies widely. This leads to the question: if support received by Parties helps them to lower current and future emissions of specific sectors, then would this need to be reflected in the baselines used for Article 6.4 activities? If so, how could this be done, given that:

- Reporting of support received by developing countries is not mandatory, nor is reporting on the use, impact and results of climate finance;

- It is not clear from many Parties' NDCs (or BURs) which are the specific activities and their mitigation potential that will be prioritised on the receipt of climate finance. 


\section{An approach based on "business as usual" emissions}

The current negotiation text also includes an option for a "business as usual" (BAU) approach. This is widely interpreted as requiring the creation of a forward-looking scenario ${ }^{23}$ that describes how GHG emissions would progress in the absence of the mitigation activity.

This approach faces two main drawbacks in the Article 6.4 context. Firstly, definition of a "BAU" scenario requires a number of assumptions about how conditions are expected to evolved, leading to considerable uncertainty in the baseline emissions levels. Secondly, as discussed in section 2, Article 6 is explicitly intended to provide an avenue to increase ambition of future pledges, which is important because the current set of NDCs are not sufficiently ambitious to reach the global goals of the Paris Agreement. This raises complications over what to include in a BAU scenario approach for crediting from the Article 6.4 mechanism, for example whether the NDC outcome should be built in as part of BAU conditions. Doing so would mean that the highest ambition of the mechanism is to follow the current NDC emission pathways. Moreover, the macro nature of most NDCs could make assumptions about how to integrate them into sector, sub-sector or project-specific BAU scenarios challenging.

\section{An approach based on historic emissions}

Another approach presented in the current draft negotiation text is one based on "historic emissions". This approach can also be implemented in different ways, e.g. extrapolating emissions at a constant historical level (such as absolute or per unit output levels relevant to the activity) or following the historical trend (similar to a simplified BAU approach). Provided that historical data for an activity is available, this approach is relatively straightforward to quantify. Compared to the BAU and the performance-based approach, less data is generally needed to establish an activity-specific baseline following the "historic emissions" approach and it is usually easier to set the activity boundaries (Prag and Briner, 2012[11]).

However, as with the BAU approach, a crediting approach based on "historic emissions" would not lead to a path consistent with the Paris Agreement goals globally and does not encourage increasing the ambition of future pledges. It also presents a high risk to environmental integrity, as it could lead to inflated levels of crediting from the mechanism if production levels decrease in the case of an absolute baseline (e.g. due to an economic crisis, unrelated to the mechanism itself), or if production levels increase, if the baseline is output-based. It also could be undermined by technology advances that would not be captured in a historic emissions approach, but would be picked up by other baseline approaches.

\section{Implications for Article 6.4 baseline methodologies, approaches and assumptions}

Article 6 of the Paris Agreement explicitly aims to encourage higher ambition in Parties' mitigation and adaptation actions. Article 6.4 mechanism is not itself the driver of ambition - that comes from the progression in NDCs themselves, as outlined in section 2. However, it is nonetheless important that the Article 6.4 mechanism does not undermine the environmental integrity of existing NDCs (for example with credits that do not represent real emission reductions) and provides an incentive (or at least does not provide a disincentive) for NDCs becoming more ambitious over time. As indicated by Article 6.4(d), the

\footnotetext{
${ }^{23}$ Or a collection of possible scenarios, depending on the assumptions used to build the counter-factual baseline (Prag and Briner, 2012[11]). There are different definitions of a BAU scenario, e.g. taking into account or not currently planned policies (Fei and Shuang-Qing, 2012[43]]).
} 
mechanism also needs to deliver an OMGE, although how this is to be done is not yet defined. Delivering an OMGE is particularly important as the current NDCs are cumulatively far from the emissions reduction pathway needed to achieve the goals of the Paris Agreement. ${ }^{24}$

The choice of baseline approaches and how they are implemented is an important part of achieving these goals. An appropriate baseline level is extremely important for the environmental integrity of the mechanism. The different baseline approaches mentioned in the current negotiation text will have different implications depending on the sector and context in which they are used. The following table (Table 2) outlines how different baseline approaches could apply to Article 6.4 according to a number of key criteria. For all the criteria, a "low" categorisation means that the approach does not easily meet the criterion, while a "high" categorisation denotes a good fit. These criteria are:

- Conservativeness: how well-suited the approach is to deliver emissions baseline levels that respect the principle of conservativeness and therefore maintain environmental integrity;

- Predictability of total abatement: how easy it is to predict or calculate the amount of GHG mitigation from the activity using that particular approach;

- Ease of application with limited data: when there is limited data available, some of the approaches would still be able to provide meaningful results, while others would not - this criterion assesses the extent to which this is possible;

- Ease of establishing activity boundaries: ease of establishing the boundaries needed to calculate the emissions baseline for an activity; for some approaches, the choice of establishing narrow or wide boundaries for the mitigation activity is quite straightforward, while for others it would be more complicated as this choice could lead to very different results;

- Objectivity in establishing the baseline: the extent to which the process of establishing the emissions baseline is dependent on potentially subjective choices (recognising that most approaches involve at least some subjective elements);

- Objectivity in applying the baseline: once the baseline level is set, the application of some approaches to calculate the emission reductions from the mitigation activity entails using a certain degree of subjectivity. This criterion assesses the extent to which calculating the emission reductions objectivity from the activity is an objective process.

\footnotetext{
${ }^{24}$ This is particularly relevant because the latest science indicates that to have the chance to be on track with the Paris Agreement goals, there is an urgent need to reduce net global emissions as soon as possible. For instance, the IPCC "Special Report on the impacts of global warming of $1.5^{\circ} \mathrm{C}$ " states that there are now only 11 years left to still be able to get back on track on a $1.5^{\circ} \mathrm{C}$ scenario with no or limited overshoot of $1.5^{\circ} \mathrm{C}$ and to reach net zero around 2050 (IPCC, 2018[44]).
} 
Table 2. Analysis of baseline methodological approaches and bulleted conditions

\begin{tabular}{|c|c|c|c|c|c|c|}
\hline \multirow{2}{*}{$\begin{array}{l}\text { Baseline } \\
\text { methodological } \\
\text { approach }\end{array}$} & \multicolumn{6}{|c|}{ Criteria } \\
\hline & $\begin{array}{c}\text { Conserva- } \\
\text { tiveness / } \\
\text { environmental } \\
\text { integrity }\end{array}$ & $\begin{array}{c}\text { Predictability } \\
\text { of total abate- } \\
\text { ment }\end{array}$ & $\begin{array}{c}\text { Ease of } \\
\text { application } \\
\text { with limited } \\
\quad \text { data }\end{array}$ & $\begin{array}{l}\text { Ease of es- } \\
\text { tablishing } \\
\text { activity } \\
\text { boundaries }\end{array}$ & $\begin{array}{l}\text { Objectivity in } \\
\text { establishing } \\
\text { the baseline }\end{array}$ & $\begin{array}{l}\text { Objectivity in } \\
\text { applying the } \\
\text { baseline }\end{array}$ \\
\hline $\begin{array}{l}\text { "Performance- } \\
\text { based" approach }\end{array}$ & $\begin{array}{l}\text { L-H (depending } \\
\text { on details) }\end{array}$ & L & L-M & L-H & L-M & $\mathrm{H}$ \\
\hline $\begin{array}{l}\text { "Best available" } \\
\text { approach }\end{array}$ & $\begin{array}{l}\text { L-H (depending } \\
\text { on details) }\end{array}$ & L & L-M & L-H & M & $\mathrm{H}$ \\
\hline $\begin{array}{l}\text { Approach based on } \\
\text { "business as usual" } \\
\text { emissions }\end{array}$ & L-M & L-M & M & $\mathrm{M}-\mathrm{H}$ & L & L-M \\
\hline $\begin{array}{l}\text { Approach based on } \\
\text { "historical } \\
\text { emissions" }\end{array}$ & $L$ & $\mathrm{M}-\mathrm{H}$ & $\mathrm{H}$ & $\mathrm{H}$ & $\mathrm{M}-\mathrm{H}$ & $\mathrm{M}-\mathrm{H}$ \\
\hline
\end{tabular}

Note: $\mathrm{L}=$ low; $\mathrm{M}=$ medium; $\mathrm{H}$ = high. The "best available" approach criteria are assessed assuming that it means "best available technology". Source: Authors.

The table highlights that the choice of a baseline approach appropriate for the context of Article 6.4 is not straightforward. Further, the suitability of each approach will depend on the detailed methodologies and underlying assumptions as these also have a crucial impact on the baseline level and therefore the maximum level of credits that an Article 6.4 activity can generate. Article 6.4 baselines would ideally need to be set at or below the emissions level consistent with the sectoral or sub-sectoral emissions trajectory towards a host Party's NDC, though in practice most NDCs do not provide enough detail to be used as a basis for an accurate baseline scenario (see Box 2). Practical solutions are therefore needed to establish baselines suitable to the Article 6.4 context. One approach could be to start from the extensive experience of the KP mechanisms and assess what needs to be changed or improved to fit the Article 6.4 context (e.g. see the deep dives in Section 4), in particular how the conservativeness of baselines can be made more robust, and more in line with the new context in which the mechanism operates (e.g. considering the level and timeline of NDCs' mitigation pledges). Article 6.4 baselines could also potentially become even more stringent over time, depending on how Parties interpret the requirements of conservativeness and OMGE.

An important role for the Supervisory Body and/or designated operational entity for Article 6.4 could therefore be to assess the conservativeness of assumptions and methods used. However, while setting the baseline levels determines how many credits are awarded for each activity, it does not by itself determine the eligibility of project types that could participate in the Article 6.4 mechanism. This is a separate issue that would need to be addressed by the design of the mechanism. ${ }^{25}$

\footnotetext{
25 In theory, if the baseline is set at a very low level, it may de facto automatically exclude certain types of technologies/projects. Therefore, there is a link between baseline levels and what project type can realistically generate credits.
} 


\section{Deep dives on the implications of different baseline methodologies for two sectors}

This section uses specific deep dives to discuss some of the implications of different baseline methodologies in two sectors under the new context of the Article 6.4 mechanism. The deep dives do not test all the baseline approaches currently under discussion for the two selected sectors, but rather assess methodologies used in the CDM to understand if and how they could apply in the Paris Agreement context. The first deep dive focuses on the power generation sector. This sector is the one with most activities registered and most credits issued under the CDM. The second deep dive analyses the implications of using different baseline methodologies in the cement sector. The cement sector is the second most emissive GHG-emitting industrial sector, responsible for around $7 \%$ of global carbon emissions (International Energy Agency, 2018[23]), with emissions expected to rise substantially in the future due to an increase in infrastructure development. However, cement activities were less common in the CDM, with fewer than $1 \%$ of activities registered and accounting for $0.6 \%$ of total credits issued.

Each deep dive first explains why the sector in question might be relevant for Article 6.4. Then they evaluate the current methodological approaches used in the CDM in the sector, and draw implications for setting baselines under the Article 6.4 mechanism.

\section{Power generation sector (i.e. supply side)}

This deep dive explores first why power generation mitigation activities were relevant under the CDM and might be important for Article 6.4 mechanism. It then describes the most widely used methodological tool under the CDM for grid-connected power plants, the "combined margin" emission factor approach. It also highlights some limitations of this approach by analysing the statistics from over a decade of experience of its application in the CDM. The deep dive then draws implications for setting baselines under Article 6.4 for the power generation sector.

\section{Why might power generation mitigation activities be important for Article 6.4 mechanism?}

The power generation sector is unlike other sectors because a wide diversity of energy sources and technologies are used to produce a homogeneous output: electricity. Moreover, as shown in Figure 2 in Section 2, nearly $75 \%$ of the activities registered in the CDM used methodologies related to electricity (e.g. development of renewable energy projects) and most of the CDM credits were also issued from the power generation sector. This means that there is already substantial experience in implementing power sector mitigation activities with the support of crediting mechanisms. Additionally, it is a large emitting sector with proven, low-GHG technologies that are commercially available. Furthermore, the availability of data for 
electricity generation is generally quite good in many countries. All these conditions combined make the power generation sector potentially important for the Article 6.4 mechanism.

The possible GHG mitigation activities in power generation are quite varied, depending on the technology and energy input used. Mitigation activities could consist of the creation of new generating units (i.e. greenfield development - emitting lower GHG emissions than those included in the baseline scenario), or in the retrofitting or changing practices and/or inputs at existing generating facilities (i.e. brownfield development). Moreover, one important distinction to consider when setting the baseline is if the powergenerating unit is connected to the grid, or is off-grid. The following analysis focuses on grid-connected power generation units only because, despite the growth in off-grid applications in recent years, gridconnected power still represents the vast majority of power generation, and demand for grid-connected electricity is continuing to grow steadily (International Energy Agency, 2018[24]).

\section{Evaluation of the current methodological baselines tools under the CDM for grid- connected power plants: the Combined Margin methodological tool}

The CDM methodology used in the most number of CDM activities ${ }^{26}$ uses a "combined margin" (CM) methodological tool. ${ }^{27}$ This emission factor approach aims to estimate the carbon intensity of electricity being displaced by a new project coming onto the grid. It is in a way a type of performance benchmark to set a baseline to determine crediting levels. However, applying a single, simple performance benchmark (e.g. an average performance benchmark, or an average of the top $X \%$ performers) across the whole sector could lead to perverse results for crediting because of the wide range of emissions profiles among power generation technologies and between countries, and because of the way that electricity grids manage different sources of electricity generation. ${ }^{28}$

The CM methodological tool has remained largely unchanged since when it was initially proposed as an AIXG (now CCXG) ${ }^{29}$ paper (Kartha, Lazarus and Bosi, 2002[9]). It has several underlying methods which aim to identify the group of existing ("operating margin", OM) and prospective ("build margin", BM) power plants whose current electricity generation would be affected by the prospective CDM project activity (UNFCCC, 2018[25]). The CM methodological tool essentially involves calculating a weighted average of the $\mathrm{OM}$ and $\mathrm{BM}$ to estimate a counterfactual emission factor (EF, in $\mathrm{kgCO}_{2} \mathrm{e} / \mathrm{MWh}$ ) of the grid-connected power sector. ${ }^{30}$ Different ways of calculating $\mathrm{OM}$ and $\mathrm{BM}$ are allowed in order to account for different

\footnotetext{
${ }^{26}$ ACM0002, used in 42\% of registered CDM activities (see Figure 2 in Section 2).

27 Other types of approaches for grid-connected power plants, although theoretically possible, have been proven in literature to have limitations when applied to different types of projects in the power sector, see (Kartha, Lazarus and Bosi, 2002[9]). For this reason, the paper analyses the combined margin approach only for grid-connected power sector projects.

${ }^{28}$ E.g. renewable energy electricity and nuclear power can have GHG emissions close to zero (depending on how the boundaries are set in the assessment); different fossil fuel combustion technologies have widely differing emissions.

${ }^{29}$ At that time the CCXG was called the Annex I Expert Group (AIXG). Some details of the method keep evolving towards continuous improvement e.g. the last update of the tool at the time of writing is version $\mathrm{n} .7$ and it was updated in August 2018.

${ }^{30}$ A grid-connected power unit is defined by the CDM Methodologic Tool as "a power plant/unit that supplies electricity to an electricity grid and, if applicable, to specific consumers." (UNFCCC, 2018[25]). Interconnections among different power pools are considered in the calculation of the BM and OM. Electricity imports from Annex I countries are considered with an emission factor of $0 \mathrm{tCO}_{2} \mathrm{e} / \mathrm{MWh}$. In the context of Article 6.4, would this methodology be adapted, electricity imports from Annex I countries would have to be considered with the actual emission factor of the grid.
} 
country contexts and data quality. In the CDM, several methodologies use the CM methodological tool as part of their baseline calculation method. These different underlying methodologies use different data sets and weightings to calculate values for $\mathrm{OM}$ and $\mathrm{BM}$.

The CM was designed to allow for variations between the different fuel mixes of different electricity grids, meaning that an emissions baseline established with the CM methodological tool would result in the same type of project generating different levels of credits in different grids and host Parties. This would reflect that a renewable electricity project operating in a grid with higher levels of fossil fuel plants (such as in many Asian countries) would mitigate more GHG emissions than the same plant operating in a grid with lower levels of fossil fuel plants (such as in many Latin American countries). The CM will thus vary from grid to grid depending on the fuel mix, efficiency and GHG-intensity of current and planned plants, and weightings chosen for OM and BM (which can vary depending on the type of project being proposed). Indeed, the average CM in all Asian CDM host countries is over $40 \%$ higher than in all Latin American CDM host countries (Institute for Global Environmental Strategies, 2019[26]). The CM can also vary substantially within host Parties, as well as between different host Parties. ${ }^{31}$

Analysis of CM factors used in CDM projects shows that the ability to vary the precise way of implementing the $\mathrm{CM}$ methodological tool under the CDM (e.g. how to calculate the OM and what the relative weighting of $\mathrm{OM}$ and $\mathrm{BM}$ is) has an important effect on the resulting baseline levels of the $\mathrm{CM}$ emission factor for the same grid over a short period of time. Different sub-methods to calculate the OM can potentially lead to significant differences in $\mathrm{CM}$ values. ${ }^{32}$ Figure 3 below indicates that the $\mathrm{CM}$ methodological tool used for a given country, grid and year has led to baseline levels varying by more than a factor of two for selected grids in several countries, and up to a factor of seven in one country (Brazil). ${ }^{33}$ Figure 3 also shows how this variation could lead to situations that do not necessarily reflect the national or local circumstances of the electric grid, and could therefore be difficult to assess the baseline as conservative. For instance, the highest CM level of Brazil, where $83 \%$ of electricity was generated by non-fossil sources in 2016 (International Energy Agency (IEA), 2019 $9_{[27]}$ ), was higher than the lowest CM level of the United Arab Emirates $\left(0.35 \mathrm{tCO}_{2} / \mathrm{MWh}\right.$, with $0.3 \%$ of non-fossil electricity (International Energy Agency (IEA), $\left.2019_{[28]}\right)$ ).

\footnotetext{
${ }^{31}$ Depending on national circumstances, there could be subnational variations of the CM, e.g. if a host Party has more than one grid. For instance, several large host Parties that participate in the CDM have multiple subnational electricity grids (e.g. China).

${ }^{32}$ A limited analysis on this subject has shown that it is not clear if the application of a specific sub-method to calculate OM leads to higher or lower CM baselines, as this varies by country. This issue would benefit from further work.

${ }^{33}$ It is acknowledged that certain countries have multiple sub-national electricity grids (e.g. China). The choice of the electric grid within a given country is part of the details and assumptions of the CM approach methodology, as described in the "Step 1: Identify the relevant electricity systems" of the CDM Methodologic Tool "TOOLO7: Tool to calculate the emission factor for an electricity system" (UNFCCC, 2018[25]).
} 
Figure 3. Examples of variation of maximum and minimum CM emission factor values used in CDM activities in some CDM host countries electricity grids

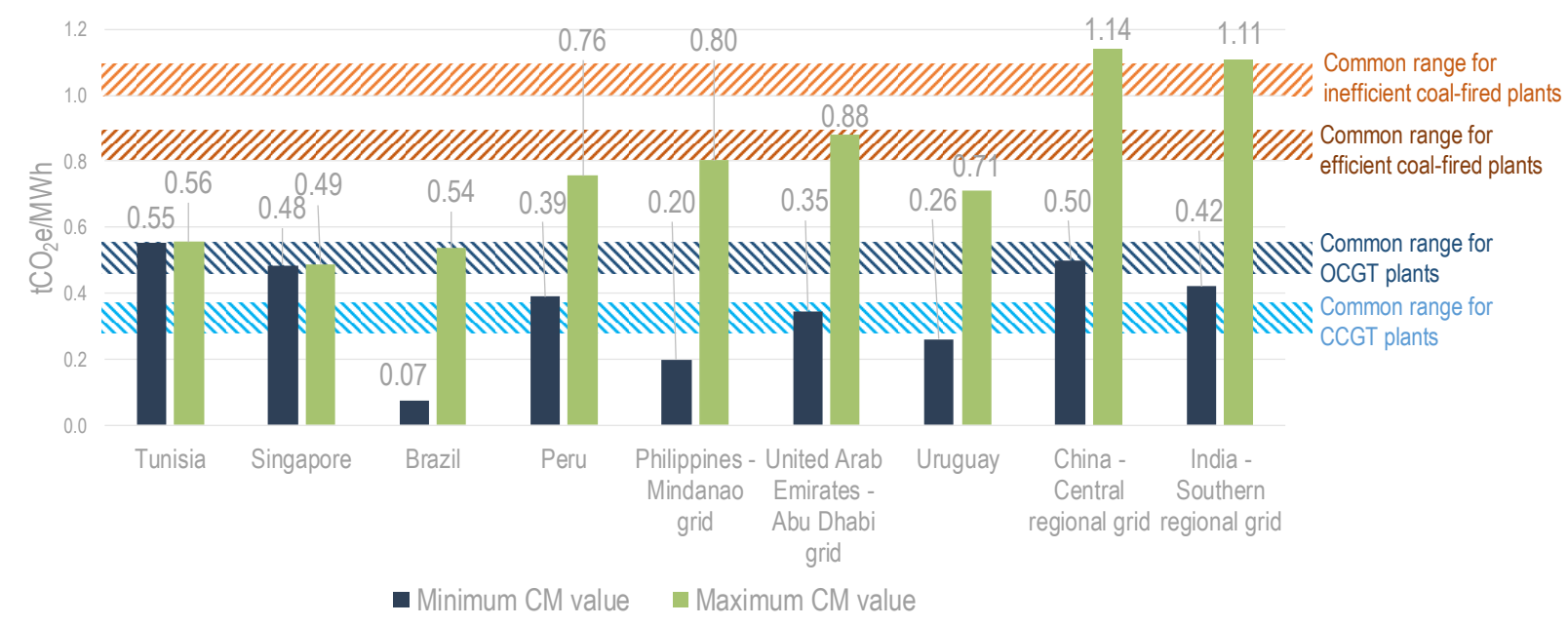

Note: The variation is calculated on the same (national or sub-national) grid. When multiple sub-national grids are available, the analysis considers the sub-national grid with the highest variation between maximum and minimum CM values, for illustration purposes. OCGT = Open cycle gas turbine; CCGT = Combined cycle gas turbine. The emission factor values reported for the common ranges of coal-fired and gas-fired power plants are indicative only, and have been calculated by applying average efficiency factors to the pre-combustion emission factors of these fuels. These ranges assume a plant efficiency of $31-33 \%$ for inefficient coal-fired plants, of $40-42.5 \%$ for efficient coal-fired plants, of 30 $33 \%$ for OCGT plants and of $57-60 \%$ for CCGT plants.

Source: Authors. CM emission factors values: IGES (Institute for Global Environmental Strategies, 2019[26]]). Ranges of emission factors for power plants: IEA (2019).

\section{Implications for setting baselines under Article 6.4}

Given the continued growth in electricity demand, the power generation sector could remain an important player for crediting under Article 6.4. It is therefore useful to assess what can be learned for Article 6.4 from the experience with power generation activities under the CDM.

The CM methodological tool, and its application, has presented both advantages and disadvantages. Advantages include that the availability of data needed to apply one or more methodologies that involved the CM methodological tool is generally quite good in many countries. Disadvantages of the CM methodological tool include that it can lead to significant variation in baseline levels within an individual country (and grid), depending on the methodology used and the details applied in its calculation. Thus, this approach has led to some grid-connected power generation projects in the central regional grid of China being credited as if they were displacing gas-fired electricity projects (e.g. with a baseline level in the range of approximatively $0.3-0.5 \mathrm{tCO}_{2} \mathrm{eq} / \mathrm{MWh}$, depending on the technology used), with other projects in the same grid being credited as if they were displacing coal-fired electricity (e.g. in the range of 0.80-1.05 $\mathrm{tCO}_{2} \mathrm{eq} / \mathrm{MWh}$, depending on the technology used). Given that a single approach has been shown to lead to such variation (depending on the details of how it is applied), Parties may consider focusing on agreeing robust principles and safeguards for baseline development, rather than the on types of approaches or methodologies that can be used. Thus, the mandate from Parties on how to apply and revise the methodologies could be allocated to technical experts and/or the Supervisory Body, with appropriate safeguards to ensure the baselines are robust, transparent, conservative, and lead to environmental integrity. 
Another implication of this variation could be that crediting approaches and methodologies developed and used under the CDM may not automatically be appropriate to be used under the mechanism of Article 6.4 of the Paris Agreement. For example, as the $\mathrm{CM}$ methodological tool can lead to high emissions baseline levels in some cases, it could be argued that this baseline approach is not necessarily conservative. It would therefore need to be altered before being applied under Article 6.4, if conservative baselines are a requirement. In addition, the CM methodological tool allows for crediting in cases where the emissions intensity of the electricity grid is increasing (i.e. where BM is higher than OM). It could be argued that allowing such situations to generate credits for potentially long periods of time is inconsistent with Article 2.1(c) of the Paris Agreement, and does not increase ambition.

Another new factor to consider in the context of the Paris Agreement is the conditionality of NDCs, as this can potentially affect the level of emissions baseline of individual Article 6.4 activities (see Box 2 in section 3). Currently, the CM methodological tool does not factor in the issue of revising baseline levels within a crediting period ${ }^{34}$, or link the issue of crediting lifetime to conditionality.

Finally, there may be different ways for setting a baseline methodology in the power generation sector that are appropriate to the context of Article 6.4, including a "NDC-adjusted emission factor approach" that could take into consideration any targets for the energy sector as laid out in the NDC when setting an emissions baseline. Such a concept would need further technical analysis to be developed and operationalised. This technical analysis could be undertaken outside the UNFCCC negotiations - e.g. outside Article 6 negotiations. New digital technology in the power generation could also be leveraged for improved baseline approaches for the power sector, such as real-time data analysis whether based on electricity system data or from satellite imagery of actual plants. The availability of such technologies will however vary across countries.

\section{Cement sector: Reduction of clinker share in blended cement}

This deep dive focuses on baselines for a particular mitigation activity in the cement sector: the reduction of the share of clinker in cement (hereafter referred to as "blending-type activities"). The analysis focuses on blending-type activities due to their mitigation potential and the particular set of challenges related to baseline setting. This section identifies advantages and challenges of using baseline methodological approaches currently proposed under Article 6.4 negotiations in setting baselines to credit blending-type activities.

\section{Why might the cement-related mitigation activities be important for Article 6.4?}

Cement is the second most $\mathrm{CO}_{2}$-emitting industrial sector, responsible for $27 \%$ of total direct $\mathrm{CO}_{2}$ industrial emissions (or $2.2 \mathrm{Gt} \mathrm{CO}_{2}$-equivalent in 2014, approximately the level of Russia's GHG emissions in 2015) (International Energy Agency, 2018[23]; OECD, 2019[29]). The direct $\mathrm{CO}_{2}$ emissions from this sector are set to rise by $4 \%$ globally by 2050 , according to the IEA Reference Technology Scenario (RTS). ${ }^{35}$ This rise in emissions is due to an increase in infrastructure development (and thus need for cement), mainly in developing countries. There is, however, scope to reduce emissions in various parts of the cement sector's supply chain and at different stages of the life cycle of the product (e.g. from extraction of raw material to final usage). Most current mitigation efforts are aimed at reducing emissions at the production stage, when

\footnotetext{
${ }^{34}$ However, the CM approach indicates that if the project developer opted for the calculation of the OM emission factor ex post, the grid emission factor is updated annually, thus the baseline is also updated annually.

35 The RTS takes into account the energy and climate pledges communicated under the Paris Agreement.
} 
emissions can be reduced in various ways, such as through energy efficiency measures, switching to lower-GHG fuels, or lowering the carbon-intensity raw material inputs. CDM activities and methods to calculate associated emission reductions have been developed for several possible mitigation activities in the cement sector, including blending-type activities. ${ }^{36}$ Possible future mitigation activities could include alternative binding materials that are less carbon-intensive and could replace clinker altogether (Lehne and Preston, 2018[30]).

A reduction of clinker in cement has a large mitigation potential (International Energy Agency, 2018[23]), and will be key to tackle emissions from the cement sector. ${ }^{37}$ The mitigation potential from this activity is high as producing clinker is very GHG-intensive (see Box 3). Clinker is a key input in cement and is mixed with other additives (which can be much less GHG-intensive to produce) such as fly ash, slag and gypsum to produce blended cement. Although cements with higher proportion of additives have high mitigation potential due to the reduced clinker use, $98 \%$ of global concrete production still uses Portland cement that contains upwards of $75 \%$ clinker (Lehne and Preston, 2018[30]).

\section{Box 3. Why does clinker production involve high $\mathrm{CO}_{2}$ emissions?}

Clinker production is responsible for the majority of emissions in the production of cement. The chemical processes that convert limestone into lime - a primary component of clinker - release a significant amount of carbon dioxide emissions (see Figure 4). The chemical process alone contributes to around $50 \%$ of the total direct $\mathrm{CO}_{2}$ emissions in cement production. Avoiding release of carbon dioxide in this process would require modifying the chemical reaction itself (e.g. by using other non-carbonated calcium-based material inputs instead of limestone). Fossil fuel combustion to power the kiln used in clinker production contributes to $40 \%$ of the total direct $\mathrm{CO}_{2}$ emissions in cement production (Lehne and Preston, 2018[30]; International Energy Agency, 2018[23]). Other steps in cement production together contribute towards the remaining $10 \%$ emissions.

\section{Figure 4. Different stages of cement production, and associated emissions}

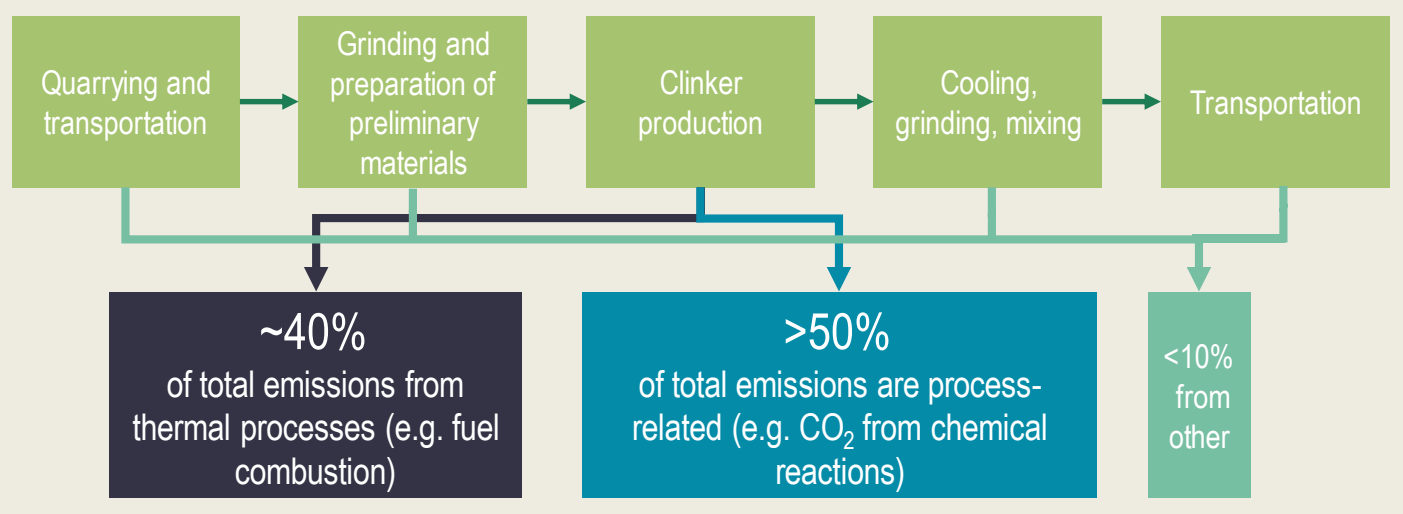

Source: Authors, adapted from (Lehne and Preston, 2018[30]).

\footnotetext{
36 These include for blending-type, fuel switching, energy efficiency activities as well as activities involving a switch to lower GHG-intensive material inputs. Figure 5 lists selected CDM activities relevant to the cement sector.

37 A reduction of clinker to cement ratio represents a $37 \%$ reduction in emissions in the cement sector according to the IEA 2 Degree Scenario (and relative to the Reference Technology Scenario). The mitigation potential of this activity in the cement sector is second only to that of innovative technologies (e.g. carbon capture), which represents a mitigation potential of $48 \%$.
} 
The majority of CDM activity registration and CER issuance in the cement sector is concentrated in only a few activity types. Figure 5 highlights that energy and heat recovery and clinker reduction are the most widely used mitigation activities in the CDM.

Figure 5. Number of registered activities and issued CERs per CDM methodology relevant to the cement sector

80

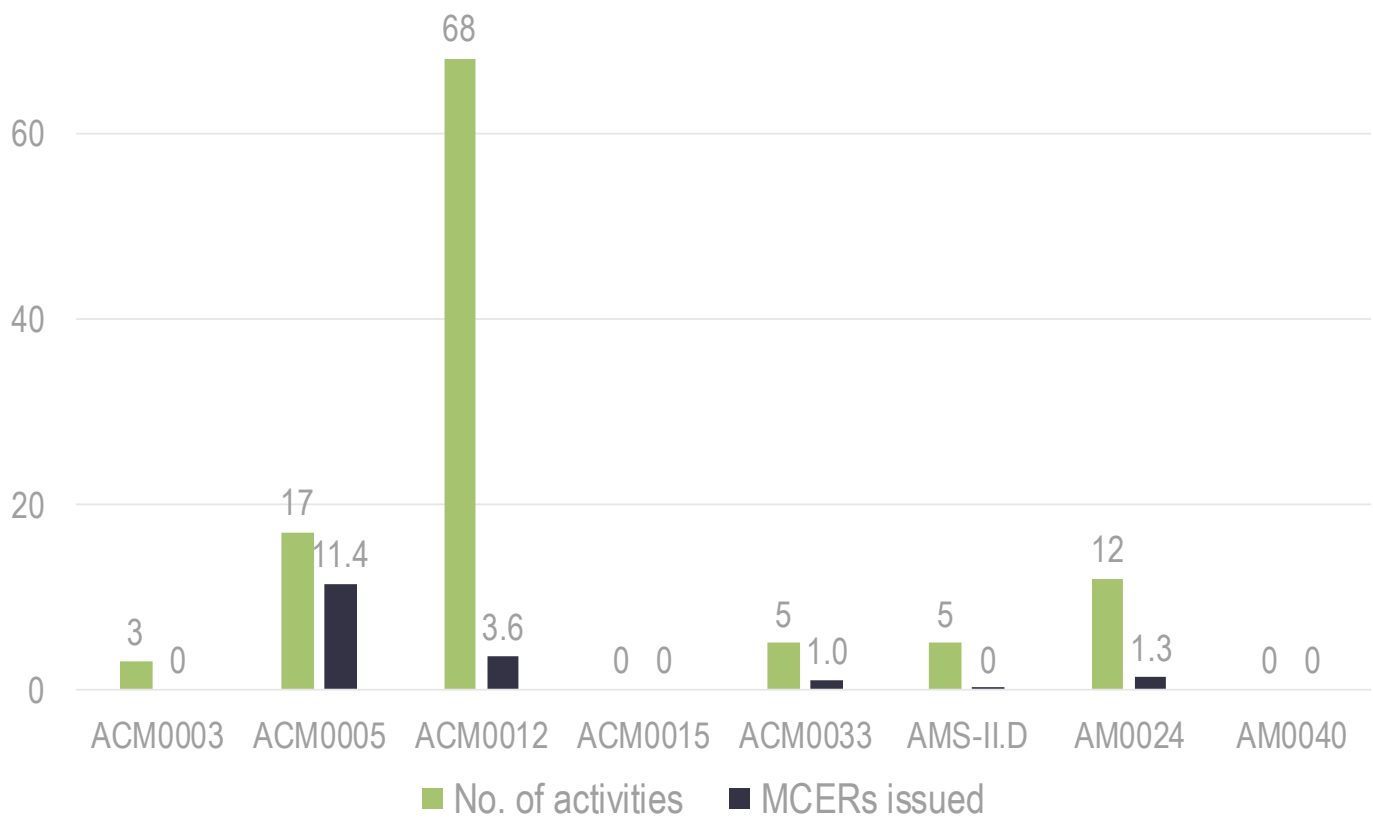

Note: Only registered activities considered. For those methodologies that encompass more than one sector (e.g. AMS-II.D.) only the activities in the cement sector were considered. The methodologies and associated activity types are:

ACM0003: Replacing the use of fossil fuels with alternative fuels in existing clinker production facilities

ACM0005: Reducing the share of clinker in blended cement (blending-type activities)

ACM0012: Recovering waste energy (this methodology is applicable to other sectors as well)

ACM0015: Switching raw materials in clinker production to less $\mathrm{CO}_{2}$-emissive ones

AM0033: Using non-carbonated calcium sources in the raw mix for cement processing

AMS-II.D: Not strictly related to only the cement sector but used in this sector for energy efficiency and fuel switching activities.

AM0024: Reducing emissions through waste heat recovery and utilisation for power generation at cement plants

AM0040: Using alternative raw materials that contain carbonates in clinker production in cement kilns Source: Authors. Analysis with data from CDM Pipeline (as of July 2019).

Given the importance of the cement sector for mitigation efforts, and the low amount of cement sector activity in the CDM relative to other sectors, it could be important to see if and how Article 6.4 mechanism could accelerate GHG emission reductions within this sector. Further work could be useful to better understand why there have been low levels of CDM activity for certain types of mitigation activities - if such activities are not already being encouraged via domestic policies. ${ }^{38}$ It would also be useful to explore if and how the Article 6 mechanism could unlock the mitigation potential of novel technologies that are not yet commercially viable, to facilitate transformative changes in the sector.

${ }^{38}$ Only three blended-type activities have been registered under the CDM over the last ten years. 
The analysis in this deep dive will focus on examining baseline determination issues for blending-type activities, due to their high mitigation potential. The remainder of the deep dive will examine current methodological approaches for this activity type as well as consider implications for baseline determination under the Article 6.4 mechanism.

\section{Evaluation of current methodological approaches under the CDM for blending-type activities}

ACM0005 is the only CDM baseline methodology applicable for blending-type activities. The activity boundary (that determines which emissions to include in the baseline calculation) in this methodology includes the cement production plant and if applicable, onsite power generation and power generation in the grid. The boundary also includes emissions from transporting additives to the plant.

Calculating the baseline emissions essentially involves two factors: emissions from clinker production (in $\mathrm{tCO}_{2}$ per tonne of clinker) in a base year and the benchmark share of clinker in blended cement (in

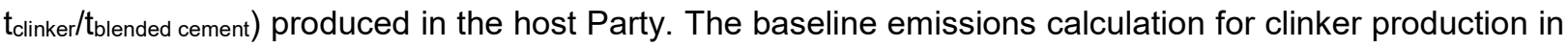
turn depends on the emissions released during the calcination process, the quantity and carbon intensity of fuels in clinker production and the quantity and carbon intensity of electricity used (UNFCCC, 2018 [31]; UNFCCC, 2018[32]). The base year for calculating the baseline emissions in the ACM0005 takes into account recent plant performance. The base year for existing cement plants can be one year or three years prior to the start of the CDM activity whereas the base year for greenfield plants is the first year of operation. A plant producing different types of blended cement (that vary in clinker share and additive type) would calculate a different baseline emission for each.

ACM0005 calculates the baseline clinker share (per tonne of blended cement) through a country-wide benchmark approach. ACM0005 requires the activity participant to use the lowest value of clinker share, from one of three benchmark-based approaches. For example, one of these approaches defines the baseline as the average mass fraction of clinker for the five plants with the highest share of additives in the blended cement.

The ACM005 methodology facilitates a continual lowering of baselines for calculating both factors. While the calculation of clinker production baseline emissions is historic-based, plants are to use the actual emissions in the crediting year, if these are lower than the historical emissions. ACM0005 also requires an annual update to the blending benchmark to incorporate any decreasing trends in clinker share up to the levels allowed by national regulations. One of the update options involves plants incorporating a default $2 \%$ increase in the share of additives in blended cement in their baseline calculations.

\section{Implications for setting baselines under Article 6.4}

There are specific challenges related to the cement sector that need to be taken into account in baseline determination for blending-type activities. These challenges have already been outlined in many dedicated studies including (Ellis, 2001[7]) and (Fuessler et al., 2019 ${ }_{[33]}$ ). The discussion below summarises key challenges to consider for baseline determination for blending-type activities.

- Data availability: Calculating baseline emissions for blending-type activities involves a lot of activity-specific emissions data from several actors in the cement production supply chain. Some of this plant-specific data may be available only to that plant due to confidentiality reasons (Fuessler et al., 2019[33]). This constraint would make it challenging to use a benchmark-based approach to calculate production emissions. However, some aggregate plant performance data could be 
available through third-party sources ${ }^{39}$, which would allow one to set performance benchmarks that take into account e.g. the top $\mathrm{X} \%$ of plants that have the lowest $\mathrm{tCO}_{2} / \mathrm{clinker} \mathrm{emissions.}^{40}$

- Availability and cost of additives: The availability and the cost of additives vary by region, and are key constraints that restrict the reduction of clinker in cement (Lehne and Preston, 2018[30]). Some additives are by-products of coal combustion and iron and steelmaking processes. Countries with domestic coal and iron and steel plants could thus access these additives at cheaper cost. Further, countries that have policies related to utilisation of waste materials from those industries could potentially enable better access to these additives. At the same time, efficiency improvements in the coal and iron and steel industries and a reduction in coal combustion would mean that there will be a reduced supply of these additives over time. Further, some of the raw materials used in clinker production e.g. limestone are abundantly available in some countries and at low cost.

- Market demand that may impact plants' clinker share and additive use: The proportion of clinker and the type of additives used in blended cement can impact its properties (e.g. strength, colour, drying time). Some cement uses may need or prefer cement with particular properties, for example cement that dries quickly would need to have no or low share of additives (if additives slow down the drying process). Similarly, some industries may prefer particular additives over others because of the impact on the cement's colour. These market preferences could therefore have an impact on price of blended cements and potentially, a plant's preference for producing one type of blended cement over another. ${ }^{41}$ At the same time, different types of blended cement are needed for different purposes (e.g. constructing bridges or for mining applications). Therefore, it is important to consider whether the baseline determination would incentivise production of one type of blended cement over another. For example, if only one performance benchmark is applied for all cement production plants producing different blended cement types, the plants could be incentivised to shift production to those cement types that would generate more credits under the Article 6.4 Mechanism.

- Regulatory standards that constrain reduction of clinker in blended cement: Different countries have different regulations on the clinker share for different types of blended cement; some specify a minimum acceptable clinker share while others define a range. Therefore, cement production plants in different countries face different barriers in how much they can reduce clinker share in blended cement. The difference in regulation is partially due to the confidence associated with the blended cement's properties (e.g. strength). More awareness on the part of consumers, the building sector and government could facilitate a re-examination of these standards and a further reduction in clinker shares in that country, where possible. Some countries such as Australia are also trying to establish performance-based standards (e.g. measured in strength quality of cement) instead of prescribing a clinker share.

\footnotetext{
39 For example, the Getting the Numbers Right (GNR) database published by the Global Cement and Concrete Association (formerly the Cement Sustainability Institute).

40 One of the reasons the CDM Methodologies Panel rejected a proposed alternative methodology for the cement sector (NM0302) was due to its heavy reliance on GNR data, as the Panel observed that some of the data did not include certain regions in the world. Further, the Panel raised questions on the appropriateness of using a third-party proprietary instrument as the data source for the methodology's design.

41 The ACM0005 methodology specifies different additionality conditions including market acceptability barriers which are met if there is a perception in the country that "high additive blended cement is of inferior quality" and if there is a "lack of awareness of customers on the use high additive blended cement".
} 
There are also different advantages and challenges that can arise depending on the methodological approach chosen for setting baselines for blending-type activities, For example, it would be more feasible to calculate a performance benchmark using plant- and country-level performance (when possible) rather than regional or international ones, due to the variation in additive availability across countries and data availability constraints. It would also be important for the methodological approach to allow for the use of dynamic baselines, to facilitate that plants strive towards a feasible and more ambitious (lower) clinker share in their blended cement. The dynamic baseline could accommodate e.g. any changes to national standards or demand-side preferences that favour a reduction in clinker share in blended cement. Table 3 summarises some of the implications of using different methodological approaches that are currently under consideration in Article 6.4 negotiations for blending-type activities.

The Article 6.4 mechanism could use an approach for blending-type activities that is similar to or based on ACM0005. ACM0005 takes into account that different plants may use different fuels and technologies which result in different clinker production emissions. The use of a plant-specific and historic (versus benchmark) approach to determine clinker production baseline emissions would thus be appropriate. ACM0005 also facilitates a continual lowering of the baseline by asking participants to use actual emissions as the baseline, if the emissions in the crediting year are lower than the base year emissions. The cost and availability of additives likely being relatively the same for most plants in a country makes the use of benchmark-based approach for clinker share baseline appropriate. The dynamic performance-based benchmark of ACM0005 therefore facilitates plants in a country to rapidly increase additive share in line with the best performing plants, up to the level acceptable by regulatory standards and market demand. 
Table 3. Pros and cons of using different baseline methodological approaches for cement blending-type activities

The table examines selected baseline methodological approaches under consideration currently under negotiation.

\begin{tabular}{|c|c|c|}
\hline Baseline approach & Advantages & Challenges \\
\hline $\begin{array}{l}\text { "Performance-based" approach (e.g. } \\
\text { benchmarking) } \\
\text { Example of a methodology: a plant's } \\
\text { baseline emissions (in tC } \mathrm{C}_{2} \mathrm{e} \text { ) for a } \\
\text { particular blended cement would be an } \\
\text { average emissions of the top ' } \mathrm{X} \text { ' best- } \\
\text { performing plants (i.e. plants with the } \\
\text { lowest emissions associated with clinker } \\
\text { production and procurement of additives). }\end{array}$ & $\begin{array}{l}\text { Experience in the cement industry in using } \\
\text { benchmarks to monitor and evaluate } \\
\text { performance, some experience in the CDM } \\
\text { Aggregated information published by third-party } \\
\text { sources could allow for baseline setting e.g. at the } \\
\text { level of top X\% performing plants in the country. } \\
\text { Performance-based baseline emissions could } \\
\text { alternatively take into account recent trends in the } \\
\text { international cement market. } \\
\text { Could encourage further emission reductions than } \\
\text { a historic emissions-based approach. }\end{array}$ & $\begin{array}{l}\text { Confidentiality concerns could restrict the plant-specific data availability needed of peers in order to establish } \\
\text { the baseline. } \\
\text { Setting performance benchmarks across the sector at the international level therefore could potentially result in } \\
\text { over-crediting (if set too low) or create missed mitigation opportunities (if set too high). } \\
\text { It would be important to update the performance benchmark in line with any changes in national regulations or } \\
\text { demand-side preferences that lower the clinker to blended cement ratio, to ensure that the methodology } \\
\text { facilitates further emission reductions from blending-type activities. }\end{array}$ \\
\hline $\begin{array}{l}\text { "Best available" approach (e.g. Best } \\
\text { Available Technology) } \\
\text { Example of a methodology: a plant's } \\
\text { baseline emissions (in } \mathrm{tCO}_{2} \text { ) would be } \\
\text { calculated by taking into account emissions } \\
\text { associated with the best available } \\
\text { technology in that country, for key } \\
\text { technologies (e.g. those that produce the } \\
\text { most emissions) relevant for clinker } \\
\text { production and procurement of additives. }\end{array}$ & $\begin{array}{l}\text { Could incentivise greater uptake of less-emissive } \\
\text { technologies and potentially other technological } \\
\text { innovation (if baseline is set at an ambitious level) } \\
\text { Could encourage further emission reductions than } \\
\text { a historic emissions-based approach }\end{array}$ & $\begin{array}{l}\text { Difficult to determine what "best available" refers to (technologies with highest energy-efficiency performance } \\
\text { vs energy-efficient technologies most widely used by the industry). } \\
\text { Depending on the boundary chosen, calculating the BAT emissions for blending-type activities could be very } \\
\text { complex as it may require identifying a BAT for every process and collecting related data to calculate } \\
\text { emissions associated with that BAT (e.g. alternative fuels used, kiln technology, technologies associated with } \\
\text { producing raw materials and transporting additives) (Fuessler et al., 2019 }\end{array}$ \\
\hline $\begin{array}{l}\text { Historic emissions } \\
\text { Example of a methodology: a plant's } \\
\text { baseline emissions (in } \mathrm{tCO}_{2} \mathrm{e} \text { ) could be } \\
\text { calculated as the average emissions } \\
\text { associated with clinker production and } \\
\text { additive procurement in the past } X \text { years. }\end{array}$ & $\begin{array}{l}\text { Plant-specific data for at least a few years prior to } \\
\text { the activity start date is likely to be available to the } \\
\text { plant. }\end{array}$ & $\begin{array}{l}\text { Setting historic emissions could potentially lead to significant over-crediting depending on the period during } \\
\text { which historic emissions is considered }- \text { as the share of clinker in cement has often declined substantially } \\
\text { (e.g. in past } 10 \text { years when cement may have largely contained }>95 \% \text { clinker versus the past } 5 \text { years, during } \\
\text { which time some installations may have started to reduce clinker share in cement) } \\
\text { The ability to choose the period of time used to calculate baseline emissions may create opportunities to game } \\
\text { the system. However, requiring all plants to use the same period of time may result in under- or over-crediting } \\
\text { Some plants may not have data available for long periods of time and may not have continuous time series of } \\
\text { data. } \\
\text { Confidentiality concerns could restrict plant-specific data availability. } \\
\text { May be difficult to ascertain whether any planned/proposed changes outside of the product boundary may } \\
\text { have had an uncharacteristic effect on historic emissions in a particular year.- }\end{array}$ \\
\hline
\end{tabular}

Source: Authors. 


\section{Benefits and implications for host Parties participating in Article 6.4}

There are important differences in the context in which the Article 6.4 mechanism and the KP mechanisms operate. This includes that under the Paris Agreement, all Parties have NDCs (see Section 2), whereas only Annex I Parties had emissions targets under the Kyoto Protocol. Under the Paris Agreement, Parties also need to account for the mitigation targets in their NDCs that they intend to achieve; this was not the case for CDM host Parties under the Kyoto Protocol. This new context of the Paris Agreement presents certain benefits and has implications for potential host Parties, which may change how these Parties engage in the Article 6.4 mechanism compared to how they engaged in the CDM.

Host Parties participating in the Article 6.4 mechanism will need to consider the trade-offs between using mitigation options to meet their NDC, or approving or authorising ${ }^{42}$ a mitigation activity that would lead to the international transfer of emission reductions under the Article 6.4 mechanism. Article 6.5 of the Paris Agreement is explicit about the choice a host Party needs to make relating to the emission reductions achieved domestically. This Article states that emission reductions resulting from Article 6.4 activities "shall not be used to demonstrate achievement of the host Party's nationally determined contribution if used by another Party to demonstrate achievement of its nationally determined contribution" (UNFCCC, 2016 $\left.{ }_{[1]}\right)$.

It would therefore be important for host Parties to consider the range of possible domestic mitigation options available. This would allow Parties to identify which type of mitigation they would prioritise for domestic use and NDC achievement, and which (if any) they would use to approve or authorise credits for the Article 6.4 mechanism. Different mitigation actions in a country can incur different costs. The illustrative marginal abatement curve in Figure 6 outlines that the cost of mitigation associated with a mitigation activity in sector $A$ in the hypothetical country is much lower than that for a mitigation activity in sector $E$. If this hypothetical country were to transfer emission reductions from cheaper abatement options to other countries via Article 6.4, this could mean that the host Party potentially would need to use more expensive abatement options to achieve its NDC. It could thus be useful for a host Party to take into account the costs related to different mitigation activities, prior to authorising or approving Article 6.4 activities.

\footnotetext{
${ }^{42}$ Article 6.4 negotiations are considering potentially distinct processes related to host Party assent to an activity. The first would potentially be host Party approval of an activity under the Article 6.4 mechanism while the other would be host Party authorisation of the international transfer of emission reductions from the activity under the Article 6.4 mechanism.
} 
Figure 6. A marginal abatement curve of a hypothetical country, illustrating the potential cost impact of internationally transferring credits from different types of activities

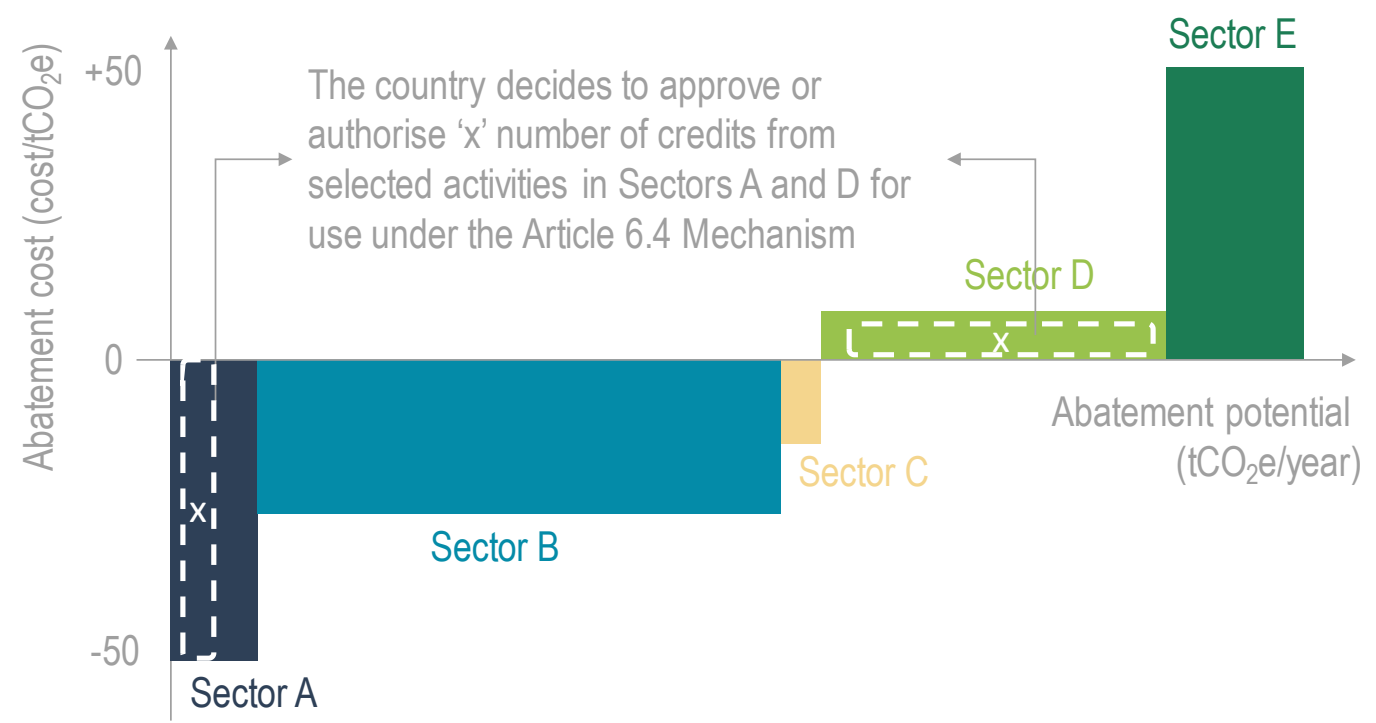

Source: Authors.

The host Party may also need to consider the longer-term implications of internationally transferring emission reductions from certain sectors via the Article 6.4 mechanism, particularly if the crediting period of an Article 6.4 activity extends beyond the current NDC period. The length of potential crediting periods (during which an activity can generate and issue credits) is still under discussion and could possibly be longer than one NDC period. If an activity is generating credits under Article 6.4, then under Article 6.5 of the Paris Agreement, the host Party cannot both use the associated mitigation to achieve its NDC and transfer credits generated under Article 6.4 internationally (for use by another Party towards its NDC). It is also currently unclear if a host Party could limit the approval or authorisation of an Article 6.4 activity to a specific crediting period (or whether a renewal of a crediting period would mean that the host Party needs to re-approve/re-authorise an activity). The host Party may therefore be foregoing all emission reductions from the activity for a period beyond the current NDC, depending on the length of any potential crediting period and if the Party cannot re-approve or re-authorise the activity and transfers. Developing and communicating short-, medium- and long-term mitigation strategies could therefore help Parties plan ahead and decide which type of/how much emission reductions a Party might want to keep for domestic achievement or authorise for the Article 6.4 mechanism and at what price.

Host Parties could also consider the potential volume of credits that an activity could generate, when deciding which activities that reduce emissions can be used domestically to meet its NDC or to generate and transfer credits under the Article 6.4 mechanism. Activity types that generate large volumes of credits at low financial risk (such as industrial gas projects) are likely to be more attractive to potential purchasers of Article 6.4 credits - also because they will have relatively low transaction costs. However, potential host countries may instead wish to prioritise other types of activities for approval or authorisation under Article 6.4 , such as energy efficiency projects or less mature renewables projects. A potential host Party may therefore need to consider whether its approval and/or authorisation procedures should focus on individual activities (i.e. authorising and/or approving on a case-by-case basis), or be based on a broad set of criteria 
Parties may also need to consider the permanence ${ }^{43}$ of emission reductions from activities undertaken domestically as well as those under Article 6.4 , as it is possible that reductions from some types of activities are subsequently reversed. This potential reversal would need to be taken into account by a host Party in planning how it meets its NDC. If these reductions are used for the Article 6.4 mechanism and the reversal occurs during the activity's crediting period, clarity would be needed on the ensuing status of the activity's approval or authorisation and the treatment of the credits. ${ }^{44}$

How activity baselines are set may also raise important implications for host Parties. Baselines that are set too high could result in credits where there have been no associated emission reductions. "Static" baselines (i.e. ones where the initial level, as opposed to the initial methodology, are fixed for the entire crediting period) also run the risk of generating credits where there have been no associated emission reductions. ${ }^{45}$ If a host Party applies a potential corresponding adjustment for these transfers, it would have to compensate for them by undertaking more mitigation efforts. The application of conservative baselines could help prevent such an eventuality (see Section 2). Further, the host country could potentially use any leftover mitigation from Article 6.4 activities that use conservative baselines towards meeting its own NDC (Schneider, Fuessler and Herren, 2014[19]).

It may be useful for host Parties to consider the pros and cons of having distinct processes for activity approval and for authorisation of transfers of emission reductions from the activities. This distinction would allow host Parties to separate the processes that approve a specific activity (e.g. large infrastructure project), the potential generation of credits of this activity under Article 6.4, and the level of credits that can be transferred from this activity. These different processes are currently under discussion in Article 6.4 negotiations. According to this discussion, a host Party would not only approve an activity for the Article 6.4 mechanism but would be able to "authorise" those A6.4ERs that would be internationally transferred for use towards other NDCs or for other purposes (paragraph 49(d) of the latest SBSTA text (UNFCCC, $\left.2019_{[2]}\right)$ ). There may be instances where important changes (e.g. in meeting regulatory standards) occur to the activity between the time it is approved and issues credits. A host Party could then determine whether the activity could still operate under the mechanism and issue credits following these changes. On the other hand, the distinction between approval and authorisation processes may also mean higher transaction costs and uncertainty for investors and activity participants.

The development of mitigation activities under Article 6.4 could nevertheless provide important benefits to host Parties. Host Parties would benefit from any emission reductions that are generated by an activity past the potential expiry of the crediting period, as the Party could use the reductions to meet subsequent NDCs. For example, if a wind farm activity has a crediting period of 10 years but is operational for and reduces emissions during a total 30-year timespan, the host Party could use the emission reductions generated in the remaining 20 years towards meeting future NDCs (depending of course on when and how

\footnotetext{
${ }^{43}$ There is no agreed international definition for permanence but it could generally be understood to refer to the longevity of emission reductions in the atmosphere. For example, an activity's emission reductions can be considered non-permanent if the emissions are removed from the atmosphere for a fixed period of time, after which point the activity would become a source of emissions.

${ }^{44}$ The CDM addressed the non-permanence issues in the forestry sector by establishing temporary CERs (tCERs) and long-term CERs (ICERs) that have a limited longevity. Temporary CERs expire at the end of the commitment period following the one during which it was issued and long-term CERs expire at the end of that activity's crediting period (UNFCCC, 2019[46]).

${ }^{45}$ For example, this could occur if receipt of international climate support by activities in the same sector as the Article 6.4 activity changed the availability of the "best available" technology in that sector/country, improved the environmental performance of the group of activities with which the Article 6.4 activity was compared etc.
} 
the baseline is revised during that period). The host Party thus benefits from the existence of the mechanism without which some of these activities would not have taken place. The host Party would need to consider both the short-term cost of transferring and foregoing initial emission reductions under the Article 6.4 mechanism as well as any long-term benefit of using future emission reductions for domestic purposes (i.e. after the end of any crediting period).

Article 6.4 also provides an opportunity to design a mechanism where mitigation co-benefits are better captured and delivered in host Parties, beyond what took place in the CDM. Indeed, one of the stated aims of the Article 6.4 mechanism is to foster sustainable development in host Parties (Article 6.4(a)). Different types of mitigation activities produce different types of co-benefits including economic, health, adaptation; the usefulness of mitigation co-benefits for the host country are well documented in literature. ${ }^{46}$ Promotion of sustainable development in host Parties through international crediting mechanisms was also an aim of the Kyoto Protocol's CDM. Host Parties under the CDM could voluntarily report on any sustainable development benefits they enjoyed through a sustainable development tool. However, the CDM did not deliver the full potential of sustainable development benefits to host Parties (Olsen and Fenhann, 2008 [34]; Karakosta et al., 2013[35]). The Article 6.4 Mechanism could potentially learn from CDM experience to understand how to better unlock potential sustainable development and mitigation co-benefits from Article 6.4 activities.

The Article 6.4 mechanism could also help improve monitoring, reporting and verification (MRV) capacity in host Parties at the mechanism level. There is potential for activity participants to gain further experience in data collection, baseline determination, and monitoring and verification activities, as the Article 6.4 mechanism could potentially introduce new methodologies and MRV requirements than those that exist under the CDM. Further, host Parties could benefit from access to centrally-provided services and infrastructure that participation in the Article 6.4 mechanism would enable (e.g. access to possible centralised registries). Such access may be particularly useful for those host Parties that do not yet have the domestic capacity or experience in creating and maintaining the required MRV systems.

${ }^{46}$ For example, (OECD, 2019[47]); (Bollen et al., 2009 $\left.{ }_{[41]}\right)$; (Rafaj et al., 2013[45]). 


\section{Conclusions}

Article 6.4 of the Paris Agreement establishes a mechanism "to contribute to the mitigation of greenhouse gas emissions and support sustainable development" (UNFCCC, 2016 $\left.{ }_{[1]}\right)$. Although not specifically stated as such in the Paris Agreement, the Article 6.4 mechanism is being designed as a crediting mechanism, i.e. where credits are awarded ex post if the actual emissions are below a pre-determined baseline level. ${ }^{47}$ Different approaches, methodologies and assumptions can be used to determine the emissions baseline. ${ }^{48}$

The mechanism established under Article 6.4 of the Paris Agreement shares some key characteristics with mechanisms established under the Kyoto Protocol (KP). These include voluntary participation, enabling increased cost-effectiveness in global GHG emissions mitigation via transfer of credits between different countries, and the international oversight of the mechanism. ${ }^{49}$

There are, however, some key differences in context and aims between the Article 6.4 mechanism and the KP crediting mechanisms, the Clean Development Mechanism (CDM) and Joint Implementation (JI). These include that all host Parties participating in the new mechanism will have a Nationally Determined Contribution (NDC) and are required to track progress in implementing and achieving it. In contrast, CDM host countries were not accountable for their national emissions under the KP. This may mean that host Parties need to pursue a different approach to authorising credit transfers under Article 6.4 than they did under the CDM, in order to ensure that transferring credits internationally does not jeopardise their ability to meet their NDC. In terms of differences in aims, the Article 6.4 mechanism aims to deliver "overall mitigation in global emissions" (OMGE). This did not occur in $\mathrm{JI}$ (which was a "zero-sum game"), nor was it a requirement in the CDM.

Article 6 of the Paris Agreement also explicitly aims to encourage higher ambition in Parties' mitigation and adaptation actions. While the Article 6.4 mechanism is not a driver of ambition in itself - that comes from NDC revisions - it is important that the design of the mechanism does not provide a disincentive for countries to increase the stringency of their NDCs over time. One way of ensuring that Article 6.4 could help to increase the ambition of future NDCs and deliver on its other aims is to have conservative baselines valid for limited crediting periods. This would help to ensure that Article 6.4 is not used to encourage highemitting activities with long lifetimes, such as coal-fired power plants - which were eligible for crediting under the CDM in some circumstances.

\footnotetext{
${ }^{47}$ Another possible design option would have been, in theory, as a trading mechanism, i.e. where a fixed emission cap is set and tradable allowances are issued ex ante.

48 This paper uses the term baseline "approaches" to refer to the way that baselines are established (e.g. in line with historic emissions). An approach can be applied in multiple different ways, laid out in baseline "methodologies" (e.g. for the case of an approach based on "historic emissions", the baseline could be the annual average of the latest ' $x$ ' years of the activity's emissions). Within methodologies, different assumptions (such as the value of ' $x$ ', choice of project boundary etc.) can also affect the level of an emissions baseline.
}

${ }^{49}$ E.g. the CDM and Track 2 of $\mathrm{Jl}$ are also subject to international oversight. 
The rules currently being negotiated under Article 6.4 will need to allow for a variety of different contexts considering the wide variety of mitigation actions, technologies and sectors that could be part of the mechanism. At present, the draft negotiation text leaves open a selection of possible approaches to determine emissions baselines, which could allow activity participants flexibility to use an approach and methodology that is relevant for their activity. Some of these approaches will lead to a single baseline level, or a narrow range in baseline emission levels, while others can lead to a broad range of possible baseline levels.

Experience under the CDM has demonstrated that a single approach to determining an emissions baseline may lead to a wide variation in baseline levels within a given country, sector, and project type - depending on how exactly the approach is applied (i.e. which methodologies, assumptions, parameters are used). One example is the CDM "combined margin" (CM) methodological tool to determine emissions baselines for grid-connected power plants. This methodological tool aimed to estimate the GHG-intensity of power generation plant(s) that would be offset by the new lower-GHG power generation units. The CM methodological tool allows for variations in baseline levels between different electricity grids. However, this single methodological tool - the most widely used under the CDM - also led to wide variations in baselines within a given country and electricity grid. For example, this approach has led to a variation by more than a factor of two for grid-connected projects in the central regional grid of China. Thus, some CDM projects generating credits using this methodological tool on the Chinese central regional grid have been credited as if they were displacing gas-fired electricity, with similar CDM projects in the same grid being credited as if they were displacing coal-fired electricity. Indeed, variations in baseline levels within a given grid of a factor of two occurred in several countries, and the maximum variation found was a factor of seven - within the same country and same grid over a short period of time.

Thus, the detailed methodologies and underlying assumptions used in developing a baseline (not just the overall approach) determine the range in level of credits that an Article 6.4 activity can generate, and the broader impact of the Article 6.4 mechanism on mitigation. If an aim of negotiations under Article 6.4 of the Paris Agreement is to ensure that baselines used for crediting under this mechanism are conservative, the agreed framework for Article 6.4 could usefully include safeguards to ensure that this is the case. These could include a mandate to the Supervisory Body and/or a technical body to assess the conservativeness of assumptions and methodologies used when applying a given baseline approach to ensure that baselines are robust, transparent, conservative, and lead to environmental integrity.

The implications of some of the options proposed for baseline approaches in the current negotiation text are difficult to interpret at present. For instance, the "best available" approach does not specify which underlying methods could be used to determine how to choose what is "best available", although such choices will significantly affect the baseline levels established under this approach. Several possible approaches that could be used to establish baselines under Article 6.4 will involve subjective elements. This includes defining what a "barrier to investment" represents, as such barriers vary by individual borrower, as well as by activity type and location. Defining a "business as usual" (BAU) baseline for a particular activity also involves subjective elements. Assessing whether these subjective elements represent conservative assumptions will be challenging. In certain options currently included in the negotiation text, baseline approaches under Article 6.4 will not be aligned with an emissions path consistent with the Paris Agreement goals (e.g. baselines based on "historic emissions" or on BAU).

Different baseline methodologies and approaches needed for different types of activities under Article 6.4 could be developed from scratch and/or adjusted from those that have been developed and approved under existing mechanisms, for example the KP mechanisms. The power generation and cement sector "deep dives" conducted for this paper indicate that the extent of changes needed to adjust the methods for the Article 6.4 context will vary, depending on the activity. For example, the CM methodological tool developed under the CDM for grid-connected power plants (e.g. new renewable energy plants) activity 
types could usefully be revised before being applied to Article 6.4 activities, in order to ensure inter alia that it leads to conservative baselines. However, fewer revisions may be needed to CDM baseline methodologies developed for emission reduction activities in the cement sector. The current CDM methodology for blending-type activities (that involve reducing the share of $\mathrm{CO}_{2}$-intensive clinker in cement) allows for conservativeness by using a dynamic, country-wide benchmark (as the clinker share baseline) that is annually updated in line with decreasing trends in clinker share.

Furthermore, the notion of NDC conditionality, whereby many Parties have pledged more ambitious climate action if they receive higher levels of international support, could impact baseline setting. More than 100 NDCs contain elements contingent on support. Receipt of climate finance could significantly lower emission levels (and therefore reduce the level of even conservative baselines) in specific sectors. This is one reason why baselines under Article 6.4 may need to be dynamic, i.e. not at a level that is fixed up front for multiple years, in order to take these - and other - potential changes into account.

The deep dives on the power and cement sectors have also highlighted large disparity in the uptake of crediting mechanisms across countries, sectors and activity types. Renewable electricity generation is a replicable activity type, with approved CDM baseline methodologies that have been widely used. In contrast, there have been relatively few CDM activities in the cement sector, despite the considerable mitigation potential in this sector. It could be important to understand the possible role of the Article 6.4 mechanism in facilitating the acceleration of GHG emission reductions in sectors with a large mitigation potential but which have not in the past attracted investment through international carbon market mechanisms.

Participation in the Article 6.4 mechanism could have important implications for how Parties demonstrate achievement of their NDC, and at what cost. Ideally, it would be useful for host Parties to identify their different mitigation options, and then consider which to use to meet their NDC, and which could potentially be used to issue and transfer credits internationally via the Article 6.4 mechanism. For example, if a Party agrees to approve or authorise the international transfer of emission reductions from cheaper mitigation options as credits under Article 6.4, it may have to subsequently use more expensive abatement options to meet its NDC.

Decisions on baseline emissions levels can also affect a Party's ability to meet its NDC. If baselines are set too high, some of the credits transferred will not represent real emission reductions. If a host Party applies a corresponding adjustment for international transfers, it would have to compensate for them by undertaking more mitigation efforts. The application of conservative baselines could help reduce the possibility of transferring credits that do not represent real emission reductions.

The development of mitigation activities under Article 6.4 could, however, provide important benefits to host Parties. Emission reductions generated from Article 6.4 mitigation activities past the expiry of a potential crediting period could in some cases count towards achieving subsequent NDCs. The Article 6.4 mechanism could also help host Parties attain sustainable development and mitigation co-benefits. The CDM also had an explicit objective to assist Parties in achieving sustainable development, so it would be useful for the Article 6.4 mechanism to learn from the CDM's experience in optimising co-benefits. 


\section{References}

Bollen, J. et al. (2009), Co-Benefits of Climate Change Mitigation Policies: Literature Review and New Results, OECD, Paris, https://www.oecd-ilibrary.org/economics/co-benefits-of-climatechange-mitigation-policies 224388684356 (accessed on 26 July 2019).

Bosi, M. (2001), "An initial view on methodologies for emission baselines: electricity generation case study", OECD/IEA Climate Change Expert Group Papers, OECD Publishing, Paris, http://www.oecd.org/env/cc/2002521.pdf.

Bosi, M. and A. Laurence (2002), "Road-testing baselines for greenhouse gas mitigation projects in the electric power sector", OECD/IEA Climate Change Expert Group Papers, OECD Publishing, Paris, http://www.oecd.org/environment/cc/2766208.pdf.

Chung, R. (2007), "A CER discounting scheme could save climate change regime after 2012", Climate Policy, Vol. 7/2, pp. 171-176, http://dx.doi.org/10.1080/14693062.2007.9685647.

Clapp, C. and A. Prag (2012), "Projecting emissions baselines for national climate policy: options for guidance to improve transparency", OECD/IEA Climate Change Expert Group Papers, OECD Publishing, Paris, http://www.oecd.org/env/cc/ccxg.

Ellis, J. (2001), "An initial view on methodologies for emission baselines: cement case study", OECD/IEA Climate Change Expert Group Papers, OECD Publishing, Paris, http://www.oecd.org/env/cc/2390789.pdf.

Ellis, J. and M. Bosi (2000), "Options for project emission baselines", OECD/IEA Climate Change Expert Group Papers, OECD Publishing, Paris, http://www.oecd.org/environment/cc/2390913.pdf.

Fei, T. and X. Shuang-Qing (2012), "Definition of Business as Usual and Its Impacts on Assessment of Mitigation Efforts", Advances in Climate Change Research, Vol. 3/4, pp. 212219, http://dx.doi.org/10.3724/SP.J.1248.2012.00212.

Fuessler, J. et al. (2019), Benchmarks to determine baselines for mitigation action under the [33] Article 6.4 mechanism Discussion Paper, Emissions Trading Authority at the German Environment Agency, Germany, https://www.dehst.de/SharedDocs/downloads/EN/projectmechanisms/discussion-paper bonn-2019 2.pdf? blob=publicationFile\&v=1 (accessed on 19 July 2019 ). 
Gao, S. et al. (2019), "International carbon markets under the Paris Agreement: Basic form and development prospects", Advances in Climate Change Research, Vol. 10/1, pp. 21-29, http://dx.doi.org/10.1016/J.ACCRE.2019.03.001.

Institute for Global Environmental Strategies (2019), List of Grid Emission Factors, https://pub.iges.or.jp/pub/iges-list-grid-emission-factors (accessed on 22 July 2019).

International Energy Agency (2018), "Low-Carbon Transition in the Cement Industry", https://www.iea.org/publications/freepublications/publication/TechnologyRoadmapLowCarbon TransitionintheCementIndustry.pdf (accessed on 25 July 2019).

International Energy Agency (2018), World Energy Outlook 2018, IEA Publishing, Paris, https://www.iea.org/weo2018/.

International Energy Agency (2015), World Energy Outlook Special Report - Energy Climate and Chang, International Energy Agency (IEA), Paris, https://www.iea.org/publications/freepublications/publication/WEO2015SpecialReportonEnerg yandClimateChange.pdf (accessed on 22 July 2019).

International Energy Agency (IEA) (2019), IEA Statistics | Brazil - Electricity generation by fuel (chart), IEA Publishing, https://www.iea.org/statistics/?country=BRAZIL\&year=2016\&category=Electricity\&indicator=E lecGenByFuel\&mode=chart\&dataTable=ELECTRICITYANDHEAT (accessed on 23 August 2019).

International Energy Agency (IEA) (2019), IEA Statistics | United Arab Emirates - Electricity generation by fuel (chart), IEA Publishing,

https://www.iea.org/statistics/?country=UAE\&year=2016\&category=Electricity\&indicator=Elec GenByFuel\&mode=chart\&dataTable=ELECTRICITYANDHEAT (accessed on 28 August 2019).

IPCC (2018), Global warming of $1.5^{\circ} \mathrm{C}$. An IPCC Special Report on the impacts of global warming of $1.5^{\circ} \mathrm{C}$ above pre-industrial levels and related global greenhouse gas emission pathways, in the context of strengthening the global response to the threat of climate change, sustainable development, and efforts to eradicate poverty, IPCC, Geneva, https://www.ipcc.ch/sr15/.

Karakosta, C. et al. (2013), "Does the CDM offer sustainable development benefits or not?", International Journal of Sustainable Development \& World Ecology, Vol. 20/1, pp. 1-8, http://dx.doi.org/10.1080/13504509.2012.752768.

Kartha, S., M. Lazarus and M. Bosi (2002), "Practical baseline recommendations for greenhouse gas mitigation projects in the electric power sector", OECD/IEA Climate Change Expert Group Papers, OECD Publishing, Paris, http://www.oecd.org/environment/cc/1943333.pdf.

Kollmuss, A. and M. Lazarus (2011), "Discounting offsets: issues and options", Carbon Management, Vol. 2/5, pp. 539-549, http://dx.doi.org/10.4155/cmt.11.49. 
Lehne, J. and F. Preston (2018), Making Concrete Change Innovation in Low-carbon Cement and Concrete \#ConcreteChange, Chatham House , London, https://www.chathamhouse.org/sites/default/files/publications/2018-06-13-making-concretechange-cement-lehne-preston-final.pdf (accessed on 25 July 2019).

Lo Re, L. and M. Vaidyula (2019), "Markets negotiations under the Paris Agreement: a technical analysis of two unresolved issues", OECD/IEA Climate Change Expert Group Papers, OECD Publishing, Paris, http://www.oecd.org/environment/cc/ccxg.htm.

Marcu, A. (2016), Carbon Market Provisions in the Paris Agreement (Article 6), Centre for European Policy Studies, Brussels, https://www.ceps.eu/system/files/SR\%20No\%20128\%20ACM\%20Post $\% 20$ COP $21 \% 20$ Analy sis\%20of\%20Article\%206.pdf (accessed on 18 July 2019).

Michaelowa, A. et al. (2019), Overview and comparison of existing carbon crediting schemes, Nordic Initiative for Cooperative Approaches (NICA), Helsinki, https://www.nefco.org/wpcontent/uploads/2019/05/NICA-Crediting-Mechanisms-Final-February-2019.pdf (accessed on 18 July 2019).

OECD (2019), Accelerating Climate Action: Refocusing Policies through a Well-being Lens, OECD Publishing, Paris, https://dx.doi.org/10.1787/2f4c8c9a-en.

OECD (2019), Greenhouse gas emissions by source, https://stats.oecd.org/Index.aspx?DataSetCode=AIR GHG (accessed on 23 August 2019).

Olsen, K. and J. Fenhann (2008), "Sustainable development benefits of clean development mechanism projects: A new methodology for sustainability assessment based on text analysis of the project design documents submitted for validation", Energy Policy, Vol. 36/8, pp. 28192830, http://dx.doi.org/10.1016/J.ENPOL.2008.02.039.

Partnership for Market Readiness (PMR) (2017), A Guide to Greenhouse Gas Benchmarking for Climate Policy Instruments, World Bank, Washington, DC. https://openknowledge.worldbank.org/handle/10986/26848 (accessed on 20 August 2019).

Prag, A. and G. Briner (2012), "Crossing the Threshold: Ambitious Baselines for the UNFCCC New Market-Based Mechanism", OECD/IEA Climate Change Expert Group Papers, OECD Publishing, Paris, https://www.oecd-ilibrary.org/fr/environment/crossing-the-thresholdambitious-baselines-for-the-unfccc-new-market-based-mechanism 5k44xg398s8v-en.

Rafaj, P. et al. (2013), "Co-benefits of post-2012 global climate mitigation policies", Mitigation and Adaptation Strategies for Global Change, Vol. 18/6, pp. 801-824, http://dx.doi.org/10.1007/s11027-012-9390-6.

Salon, D. (2001), "An initial view on methodologies for emission baselines: transport case study", OECD/IEA Climate Change Expert Group Papers, OECD Publishing, Paris, http://www.oecd.org/environment/cc/2468491.pdf. 
Schneider, L., J. Fuessler and M. Herren (2014), Crediting emission reductions in new market based mechanisms - Part I: Additionality assessment and baseline setting without pledges, Infras, Zurich, https://www.researchgate.net/publication/265293633 Crediting emission reductions in new market based mechanisms -

Part I Additionality assessment baseline setting without pledges (accessed on 16 July 2019).

Schneider, L. et al. (2018), Operationalising an 'overall mitigation in global emissions' under Article 6 of the Paris Agreement, New Climate Institute, Berlin / Cologne, https://newclimate.org/wp-content/uploads/2018/11/Operationalising-OMGE-in-Article6.pdf (accessed on 18 July 2019).

UNEP DTU (2019), UNEP DTU CDM/JI Pipeline Analysis and Database, http://cdmpipeline.org/ (accessed on 11 February 2019).

UNFCCC (2019), CDM: Standardized baselines, https://cdm.unfccc.int/methodologies/standard base/2015/sb4.html (accessed on 6 November 2019).

UNFCCC (2019), Draft CMA decision on the rules, modalities and procedures for the mechanism established by Article 6, paragraph 4, of the Paris Agreement, UNFCCC Secretariat, Bonn, https://unfccc.int/sites/default/files/resource/SBSTA50.DT .i11b.highlight.pdf (accessed on 22 July 2019).

UNFCCC (2019), Glossary, CDM Terms.

UNFCCC (2019), Parties and Observers to the UNFCCC, https://unfccc.int/parties-observers (accessed on 13 August 2019).

UNFCCC (2018), Approved consolidated baseline and monitoring methodology ACM0005, UNFCCC Secretariat, Bonn, https://cdm.unfccc.int/filestorage/C/W/Y/CWYGJF6DTN8QH5OSUV3RLB1PIX729E/EB50 re pan10 ACM0005 ver5.pdf?t=eER8cHY2dm9rfDBFJPAl1S3 MhQtsnUdPWYi (accessed on 25 July 2019).

UNFCCC (2018), CDM Methodology Booklet, UNFCCC Secretariat, Bonn, https://cdm.unfccc.int/methodologies/documentation/meth booklet.pdf (accessed on 25 July 2019).

UNFCCC (2018), Tool to calculate the emission factor for an electricity system, UNFCCC Secretariat, Bonn, https://cdm.unfccc.int/methodologies/PAmethodologies/tools/am-tool-07v7.0.pdf (accessed on 22 July 2019).

UNFCCC (2016), Decision 1/CP.21 Adoption of the Paris Agreement, Report of the Conference of the Parties on its twenty-first session, held in Paris from 30 November to 13 December 2015, UNFCCC Secretariat, Bonn, https://unfccc.int/resource/docs/2015/cop21/eng/10a01.pdf. 
UNFCCC (2011), Decision 3/CMP.6 Further guidance relating to the clean development mechanism, UNFCCC Secretariat, Bonn, https://unfccc.int/resource/docs/2010/cmp6/eng/12a02.pdf\#page=2 (accessed on 6 November 2019).

UNFCCC (2002), Decision 17/CP.7 Report of the Conference of the Parties on its Seventh session, held at Marrakesh from 29 October to 10 November 2001, UNFCCC Secretariat, Bonn, https://unfccc.int/sites/default/files/resource/docs/cop7/13a02.pdf (accessed on 13 August 2019).

UNFCCC (1998), Kyoto Protocol to the United Nations Framework Convention on Climate Change, UNFCCC Secretariat, Kyoto, https://unfccc.int/sites/default/files/kpeng.pdf.

Violette, D., C. Mudd and M. Keneipp (2001), "An initial view on methodologies for emission baselines: Energy Efficiency case study", OECD/IEA Climate Change Expert Group Papers, OECD Publishing, Paris, http://www.oecd.org/env/cc/2002529.pdf.

Warnecke, C. et al. (2014), "Beyond pure offsetting: Assessing options to generate NetMitigation-Effects in carbon market mechanisms", Energy Policy, Vol. 68, pp. 413-422, http://dx.doi.org/10.1016/j.enpol.2014.01.032.

Willems, S. (2001), "Framework for baseline guidelines", OECD/IEA Climate Change Expert Group Papers, OECD Publishing, Paris, http://www.oecd.org/env/cc/2390669.pdf. 


\section{Annex A}

Variations of the combined margin emission factor used in the CDM

The CM baseline approach could lead to significant variation of crediting levels within a given country, depending on the details of the assumptions and parameters applied in its calculation. Table 4 shows some examples of countries where there is a high variation between the lowest and highest value of $\mathrm{CM}$ used to calculate the crediting baseline of a CDM activity in a given country. 
Table 4. Examples of variation of CM emission factor values used in CDM activities in CDM host countries

\begin{tabular}{|c|c|c|c|c|c|c|c|c|}
\hline \multirow[b]{2}{*}{ Country } & \multicolumn{3}{|c|}{ Maximum $\mathrm{CM}$ value } & \multicolumn{3}{|c|}{ Minimum CM value } & \multirow[b]{2}{*}{$\begin{array}{c}\text { Difference } \\
\text { between } \\
\text { maximum } \\
\text { CM and } \\
\text { minimum } \\
\mathrm{CM} \text { values } \\
\text { (max CM - } \\
\text { min CM) } \\
\left(\mathrm{tCO}_{2} / \mathrm{MWh}\right)\end{array}$} & \multirow[b]{2}{*}{$\begin{array}{l}\underset{C M}{\operatorname{Maximum}} \\
\text { minimum } \\
\mathrm{CM} \text { ratio } \\
(\max C M / \\
\min C M)\end{array}$} \\
\hline & $\begin{array}{l}\text { Maximum } \\
\text { value of CM } \\
\text { emission } \\
\text { factor } \\
\left(\mathrm{tCO}_{2} / \mathrm{MWh}\right)\end{array}$ & $\begin{array}{l}\text { Registration } \\
\text { year of } \\
\text { project }\end{array}$ & Name of the grid & $\begin{array}{l}\text { Minimum } \\
\text { value of CM } \\
\text { emission } \\
\text { factor } \\
\left(t \mathrm{CO}_{2} / \mathrm{MWh}\right)\end{array}$ & $\begin{array}{l}\text { Registration } \\
\text { year of } \\
\text { project }\end{array}$ & Name of the grid & & \\
\hline Brazil & 0.536 & 2006 & National Grid & 0.075 & 2006 & National Grid & 0.461 & 7.15 \\
\hline Peru & 0.756 & 2015 & $\begin{array}{l}\text { Peruvian National Inter-connected } \\
\text { Grid (SEIN) }\end{array}$ & 0.389 & 2011 & $\begin{array}{l}\text { Peruvian National Inter-connected } \\
\text { Grid (SEIN) }\end{array}$ & 0.367 & 1.94 \\
\hline Philippines & 0.802 & 2013 & Mindanao Grid & 0.199 & 2009 & Mindanao Grid & 0.603 & 4.03 \\
\hline $\begin{array}{l}\text { United } \\
\text { Arab } \\
\text { Emirates }\end{array}$ & 0.881 & 2009 & Abu Dhabi electricity grid & 0.356 & 2012 & Abu Dhabi electricity grid & 0.525 & 2.47 \\
\hline Uruguay & 0.711 & 2008 & National Grid & 0.259 & 2008 & National Grid & 0.452 & 2.75 \\
\hline China & 1.138 & 2010 & Central Power Grid of China & 0.500 & 2009 & Central Power Grid of China & 0.638 & 2.28 \\
\hline China & 1.010 & 2010 & $\begin{array}{l}\text { Northwest Power Grid of China } \\
\text { (NWPG) }\end{array}$ & 0.474 & 2017 & $\begin{array}{l}\text { Northwest Power Grid of China } \\
\text { (NWPG) }\end{array}$ & 0.536 & 2.13 \\
\hline India & 0.978 & 2017 & National grid & 0.965 & 2017 & National grid & 0.013 & 1.01 \\
\hline India & 1.110 & 2006 & Southern grid & 0.418 & 2006 & Southern grid & 0.692 & 2.66 \\
\hline
\end{tabular}

Notes: For all the countries analysed, the variation is calculated on the same national or sub-national grid. The Southern grid in India was interconnected with other regional grids in 2013 to form one national interconnected grid.

Source: Authors. CM emission factors values: IGES (Institute for Global Environmental Strategies, 2019[26]). 


\title{
www.oecd.org/environment/cc/ccxg.htm
}

\author{
www.iea.org
}

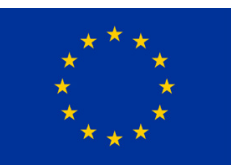

With the financial assistance of the European Union 